Check for updates

Cite this: RSC Adv., 2018, 8, 23780

\title{
Current progress, challenges and future prospects of diagnostic and therapeutic interventions in Alzheimer's disease
}

\author{
K. Rajasekhar and Thimmaiah Govindaraju (DD *
}

Alzheimer's disease (AD) is the most prevalent, progressive and multifaceted neurodegenerative disorder associated with cognition, memory and behavioural impairments. There is no approved diagnosis or cure for $A D$, and it affects both developed and developing countries and causes a significant social and economic burden. Extracellular senile plaques of amyloid beta $(A \beta)$ and intracellular neurofibrillary tangles of phosphorylated Tau (pTau) in the brain are considered to be the pathophysiological hallmarks of $A D$. In an attempt to explain the complexity and multifactorial nature of AD, various hypotheses ( $A \beta$ aggregation, Tau aggregation, metal dyshomeostasis, oxidative stress, cholinergic dysfunction, inflammation and downregulation of autophagy) based on pathophysiological changes that occur during the onset and progression of AD have been proposed. However, none of the hypotheses is capable of independently explaining the pathological conditions observed in AD. The complex and multifaceted pathophysiological nature of $A D$ has hampered the identification and validation of effective biomarkers for early diagnosis and the development of disease-modifying therapies. Nevertheless, the amyloid hypothesis is the most widely accepted and is closely correlated with disease symptoms of AD that encompass all the disease hypotheses. Therefore, amyloid plaques are ideal biomarkers for the development of an early diagnosis of AD. Similarly, the formation of amyloid plaques can also serve as a target for the design of therapeutic tools via an inclusive approach that considers multiple disease pathways involved in $A D$. Our review article briefly introduces pathophysiological factors involved in $A D$ using interdependent but diverse hypotheses. Recent advances in the development of effective molecular tools and techniques for diagnostic and therapeutic interventions in AD, especially those in the advanced stages (clinical trials) of development, are given special consideration. In addition, contributions from our laboratory to the development of selective molecular tools for diagnostic and therapeutic interventions that target multifaceted toxicity in $A D$ are also covered. In summary, we discuss diverse aspects of molecular mechanisms that underlie the pathogenesis of multifactorial AD, current progress and possible bottlenecks that have hampered the development of early diagnostic tools and effective drugs. Challenges and future prospects include the integration of various disease pathways for the successful development of an early diagnosis and effective drugs for the treatment of AD.

Received 26th April 2018 Accepted 4th June 2018

DOI: $10.1039 / \mathrm{c} 8 \mathrm{ra03620a}$ rsc.li/rsc-advances extracellular amyloid plaques and intracellular neurofibrillary tangles (NFTs)/paired helical filaments (PHFs) in the brain (Fig. 1a). The typical symptoms of AD patients include a decline in cognition, memory loss, a lack of task-performing ability and behavioural discrepancies. In the next decade, it is predicted that $\mathrm{AD}$ will severely affect both developed and developing countries and cause a significant social and economic burden (Fig. 1a). Whereas all major diseases such as prostate and breast cancer, heart diseases, and AIDS have undergone a decline, the number of patients affected by AD has risen by $>71 \%$ (Fig. 1a)., ${ }^{5,6}$ The continuous and rapid rise in disease pathogenesis is due to the absence of early detection methods and medication that can either slow or prevent progression of the disease. As a consequence, the scientific community is devoting immense efforts to understanding the pathways and progression of $\mathrm{AD}$ to
Bioorganic Chemistry Laboratory, New Chemistry Unit, Jawaharlal Nehru Centre for Advanced Scientific Research (JNCASR), Jakkur P.O., Bengaluru 560064, Karnataka India.E-mail: tgraju@jncasr.ac.in; Fax: +91 80 22082627; Tel: +91 8022082969 
a)

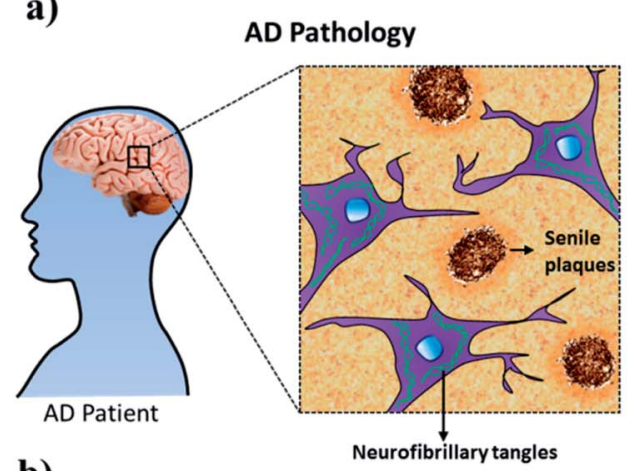

Predicted population trend for $A D$ in $\mathbf{2 0 5 0}$

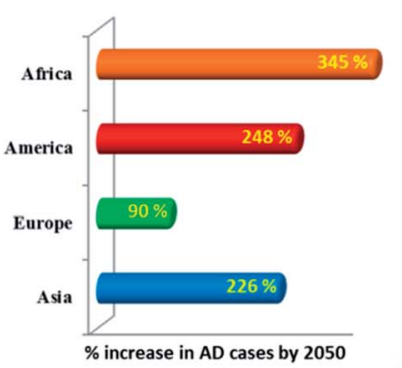

Projected trends of disease cases

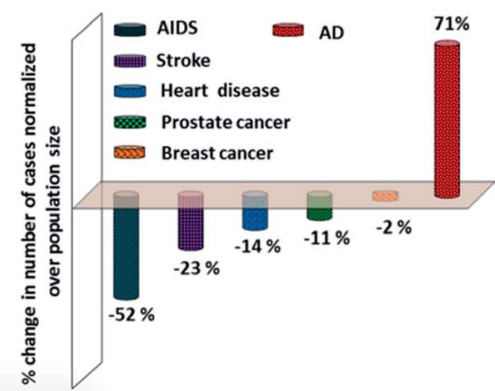

b)

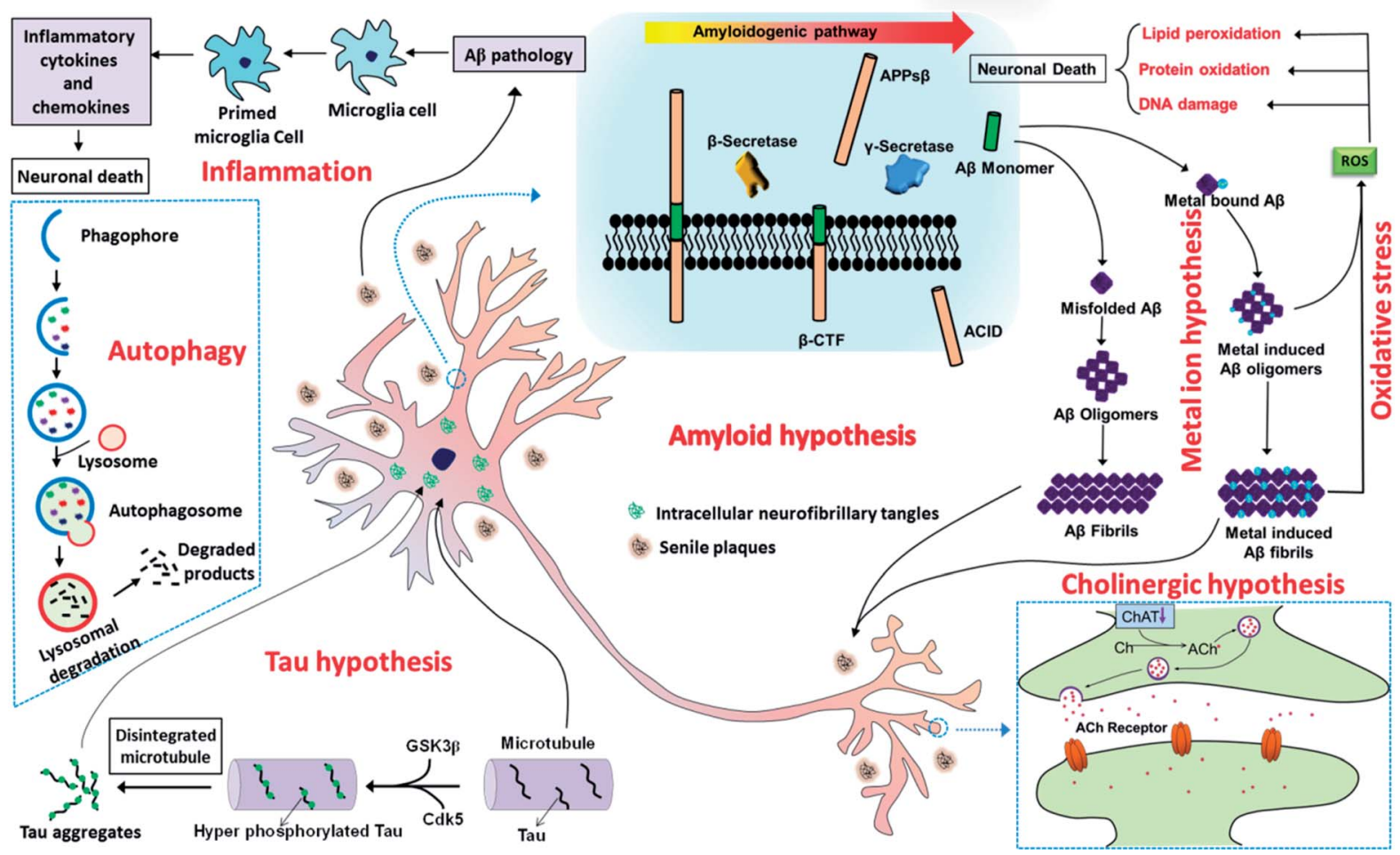

Fig. 1 (a) Characteristic features of the pathology of $A D$ in the human brain and recent statistics showing the dramatic and rapid rise of $A D$ as a global epidemic. (b) Multiple pathological pathways of AD.

facilitate the development of effective treatments. The exact mechanism of $\mathrm{AD}$ pathogenesis is not understood owing to multiple disease pathways (multifactorial nature). However, the presence of extracellular senile plaques and intracellular NFTs/ PHFs in the brain in $\mathrm{AD}$ has been shown to play a key role in all disease pathogenesis. ${ }^{2,7}$ The amyloid hypothesis is the most widely accepted and is reasonably closely correlated with the disease symptoms observed during $\mathrm{AD}$ and related multiple disease pathways involving Tau hyperphosphorylation, inflammation, post-translational modifications, protein imbalances, and dysfunction of the cholinergic system, among others. Therefore, amyloid aggregates (senile plaques and NFTs) are ideal biomarkers for the development of early diagnostic and therapeutic interventions in $\mathrm{AD}^{8-10}$ Recent advances in the development of effective diagnostic and therapeutic tools, especially those in the advanced stages of development, and contributions from our laboratory are covered with respect to current progress, challenges and future prospects. There is a vast literature on $\mathrm{AD}$, and the reader is directed to review articles published elsewhere for reports that do not fall within the scope of this article.

\section{AD pathology}

The multifactorial nature of $\mathrm{AD}$ has led to the proposal of various hypotheses based on the molecular and pathophysiological changes observed in the brain during the onset and progression of $\mathrm{AD}$ (Fig. 1B). We present some of the important hypotheses in the following sections.

\subsection{Amyloid hypothesis}

The amyloid hypothesis postulates that the generation, misfolding, aggregation and deposition of $A \beta$ peptides as senile 
plaques in the brain lead to neurodegeneration, which is considered to be one of the main causative factors of $\mathrm{AD}$ (Fig. 1b). ${ }^{11}$ The aggregation of $A \beta$ is thought to be the core of the pathology of $\mathrm{AD}$ and acts as a trigger for various other closely associated pathological pathways such as Tau phosphorylation, metal dyshomeostasis, mitochondrial damage, the generation of reactive oxygen species (ROS), oxidative stress, and inflammation, among others, which contribute to neuronal toxicity and cell death. A $\beta$ peptides are derived from amyloid precursor protein (APP), which is a transmembrane neuronal glycoprotein, by the action of protease enzymes known as secretases. Under normal physiological conditions, APP is cleaved by $\alpha$ secretase and $\gamma$-secretase and generates nontoxic fragments, which are cleared from the brain. However, adverse pathophysiological conditions alter the mode of processing of APP, as it is cleaved by $\beta$-secretase and $\gamma$-secretase to produce $A \beta$ peptide fragments (37-43 amino acids). These $A \beta$ peptide fragments, especially $\mathrm{A} \beta 42$, are highly amyloidogenic and undergo misfolding to form a $\beta$-sheet structure and hydrophobic interactions to form toxic oligomers, protofibrils, fibrils and senile plaques in extracellular regions of the brain (Fig. 1b). Among aggregated $A \beta$ species, oligomers are considered to be the most toxic forms in comparison with protofibrils and fully grown fibrils. However, recent studies have shown that fully grown fibrils or aggregates serve as a catalytic surface to produce highly toxic oligomeric species via a secondary mechanism. ${ }^{2,12} \mathrm{~A} \beta$ oligomers interfere with a signalling cascade in the synaptic cleft, which leads to synaptic dysfunction and neuronal death. For instance, $A \beta$ oligomers bind to glutamate receptors [NMDA receptor ( $N$-methyl-D-aspartate receptor) and AMPA receptor $\quad(\alpha$-amino-3-hydroxy-5-methyl-4-isoxazolepropionic acid receptor)] and instigate the loss of synaptic plasticity and memory formation. In general, the amyloid hypothesis is the most widely studied and validated hypothesis for understanding the underlying mechanism of the pathogenesis and progression of $\mathrm{AD}$. Moreover, various observations in cell biology and genetics have confirmed that $A \beta$ plays a vital role in the pathology of $\mathrm{AD} .^{13}$

\subsection{Tau hypothesis}

Tau is a microtubule-associated protein (MAP), and its function is to modulate the stability of microtubules. ${ }^{14}$ Tau protein is predominantly found in the axons of neurons and is associated with axonal microtubules. ${ }^{15}$ The uncontrolled phosphorylation of Tau leads to the disintegration of microtubules and the subsequent intracellular aggregation of pTau to form NFTs and is the pathological basis of the Tau hypothesis of AD (Fig. 1b). ${ }^{\mathbf{1 6}}$ Notably, the phosphorylation of Tau is a dynamic process and has biological significance for the structural stability and function of neurons. However, under disease conditions the specific phosphorylation of Tau becomes irreversible and leads to hyperphosphorylation, which triggers its collapse and intracellular aggregation to form NFTs. There are sufficient reports to conclude that Tau plays a definitive role in the pathology of AD. However, the Tau hypothesis alone is inadequate to explain all the symptomatic conditions observed in AD. ${ }^{17}$ Evidently, the amyloid and Tau hypotheses are closely linked to each other and together play a vital role in the pathology of AD. Clearly, there is a controversy over the identification of the first of these two hypotheses that initiates the pathology of $\mathrm{AD}$, as there exist reports that support the theory that $A \beta$ triggers Tau pathology and vice versa. ${ }^{\mathbf{1 1}}$ However, recent studies point to the fact that the aggregation of $\mathrm{A} \beta$ and associated events trigger Tau pathogenesis. ${ }^{17,18}$ Nevertheless, Tau aggregates are also observed in relatively early stages of $\mathrm{AD}$ and are possibly potent biomarkers for early diagnostic and therapeutic targets for AD. Various therapeutic strategies that have been adopted to test the Tau hypothesis include (i) the inhibition of Tau phosphorylation or phosphorylating enzymes [glycogen synthase kinase-3 $\beta$ (GSK3 $\beta$ ), cyclin-dependent kinase-5 (Cdk5), protein kinase A (PKA) and $\mathrm{Ca}^{2+} /$ calmodulin-dependent protein kinase II (CaMKII)], (ii) the inhibition of Tau aggregation and improvement of its clearance, and (iii) the stabilisation of microtubules. ${ }^{19}$ Some of the lead candidates developed for $\mathrm{AD}$ as a result of these therapeutic strategies are at various stages of clinical trials and are discussed in the therapeutics section.

\subsection{Metal hypothesis}

The presence of high concentrations of metal ions $(\mathrm{Cu}, \mathrm{Fe}, \mathrm{Zn}$ and $\mathrm{Al}$ ) in senile plaques indicates their possible role in the pathology of $\mathrm{AD}$ (Fig. 1b). ${ }^{\mathbf{2 0 - 2 3}}$ Metal ion dyshomeostasis is a common phenomenon observed during $\mathrm{AD}$ pathogenesis. ${ }^{24}$ Copper and zinc ions are known to accelerate the aggregation of $\mathrm{A} \beta$ to form senile plaques. ${ }^{25}$ Redox-active metals, especially copper and iron, stabilize oligomeric forms of $\mathrm{A} \beta$ peptides. These oligomeric species are reported to interact with various synaptic receptors and cause signalling dysfunction. ${ }^{26}$ Moreover, $\mathrm{A} \beta$-bound redox-active metals $(\mathrm{Cu}$ and $\mathrm{Fe}$ ) undergo redox cycling in a reducing environment to generate excess ROS, which further result in oxidative stress and cause neuronal death. The obvious therapeutic intervention in accordance with the metal hypothesis would be the development of metal chelators that target $\mathrm{A} \beta$-bound redox-active metals and maintain them in a redox-dormant state. However, testing the metal hypothesis using metal chelators has not been entirely successful, which was attributed to the multifaceted toxicity observed in $\mathrm{AD} .^{27}$ In recent times, the development of multifunctional molecules that target metal sequestration together with other pathological pathways (amyloid aggregation, oxidative stress, mitochondrial dysfunction and many others) has received greater interest, as such strategies are reported to yield good results.

\subsection{ROS and oxidative stress hypothesis}

The generation and tightly controlled homeostasis of ROS and reactive nitrogen species (RNS) is a common physiological process and plays a pivotal role in cell signalling and the fight against infections. ${ }^{28}$ However, the production of excess ROS and RNS causes oxidative stress and damage to cellular biomacromolecules, which severely affects normal physiological functions and causes neuronal cell death. ${ }^{29}$ The brain is highly vulnerable to oxidative stress owing to its high oxygen 
consumption rates in comparison with other organs in the body. Elevated levels of ROS are generally observed in pathophysiological conditions in $\mathrm{AD}$, and various pathways are responsible for inducing such highly unfavorable cellular conditions. For instance, $\mathrm{A} \beta$ peptides chelate with redox-active metals $(\mathrm{Cu}$ and $\mathrm{Fe})$ to form $A \beta$-metal complexes, which initiate redox cycling in a reducing environment and become the source of the continuous generation and accumulation of ROS (Fig. 1b). Mitochondrial dysfunction is a key consequence observed in the pathology of $\mathrm{AD}$, and together with mitochondrial damage initiates the cascade of pathways that generate ROS. ${ }^{30}$ The use of natural antioxidants that are generally found in many foods and medicinal plants, such as curcumin, resveratrol, epigallocatechin-3-gallate (EGCG), brazilin, orcein, tanshinone and many others, has been shown to provide significant relief to AD patients by preventing the generation of excess ROS and related oxidative stress. ${ }^{31}$

\subsection{Cholinergic hypothesis}

The cholinergic hypothesis refers to dysfunction of the cholinergic system at the synaptic overlap of neurons in the brain, which triggers memory loss and subsequent cognitive impairment. ${ }^{32}$ Therefore, rejuvenation of the cholinergic system is essential to reduce the risk of cognitive dysfunction and improve the memory of the patient. Choline acetyltransferase (ChAT) and acetylcholinesterase (AChE) are the key enzymes in the cholinergic system and play critical roles in neural transmission. Acetylcholine (ACh) is a key neurotransmitter synthesised from acetyl-CoA and choline, which is catalysed by ChAT. ACh receptors (AChR) in the synaptic cleft bind to ACh and process neuronal signals. AChE that is present in the synaptic cleft terminates signal transmission by hydrolysing $\mathrm{ACh}$ to form acetic acid and choline. The production and breakdown of the neurotransmitter ACh, which involve ChAT and AChE, respectively, operate via a feedback loop mechanism. ${ }^{33}$ A steep decline in levels of ACh and ChAT is observed during the pathology of $\mathrm{AD}$ and is responsible for memory loss and cognitive dysfunction (Fig. 1b). Therefore, the modulation of ChAT activity to prevent the degradation of ACh can restore normal synaptic signalling and cognitive function. Similarly, the NMDA receptor is a glutamate receptor and plays a vital role in synaptic signalling and synaptic plasticity. ${ }^{34}$ In fact, excessive NMDA activity causes excitotoxicity and neuronal cell death. The activation of synaptic NMDA initiates synaptic plasticity and is neuroprotective, whereas the activation of extrasynaptic NMDA causes a decline in mitochondrial membrane potential and neuronal death. ${ }^{35}$ The development of an NMDA antagonist that could selectively block extrasynaptic NMDA would be an ideal disease-modifying therapeutic strategy. Glutamate has not been mentioned, but, like a decrease in ACh levels, an increase in glutamate levels causes excitotoxicity.

\subsection{Inflammation hypothesis}

Inflammation is the natural defence mechanism in living systems, whereby the immune system recognises pathogens, debris, damaged and misfolded proteins, and damaged cells and initiates their degradation and clearance. Under $\mathrm{AD}$ conditions, amyloid deposits (senile plaques and neurofibrillary tangles) and damaged or dead neurons activate microglia to initiate inflammation. ${ }^{36}$ Microglia are activated to form primed microglia, which release cytokines, acute-phase reactants, and other inflammatory mediators that cause neuronal death (Fig. 1b). ${ }^{37}$ Activation of the inflammatory system subsequently causes localised damage in the brain, which contributes to neuronal death. In vivo models have indicated that inflammation significantly contributes to and accelerates the pathogenesis of $\mathrm{AD}$; moreover, targeting $\mathrm{AD}$ using anti-inflammatory drugs has shown promising results in preliminary studies. However, clinical studies of anti-inflammatory drugs for treating $\mathrm{AD}$ are still in their infancy. ${ }^{38}$ Nevertheless, the effect of antiinflammatory drugs has been evaluated, and the results show significant improvements in slowing the pathology of AD. ${ }^{39}$

\subsection{Autophagy}

Autophagy is the natural cellular mechanism of the degradation and recycling of toxic debris and cellular organelles. ${ }^{40}$ In fact, the modulation of autophagy plays a key role in many disease conditions, such as AD, cancer, Parkinson's disease, osteoarthritis, cardiac diseases and many others. Recently, Yoshinori Ohsumi was awarded the Nobel Prize (2016) in medicine for his contributions to understanding the mechanism of autophagy, which signifies the importance of studying autophagy in biological systems and disease research. In brief, in the autophagy process a small double-membrane sac initially appears and then elongates to form a phagophore, which engulfs part of the cytoplasm containing damaged proteins or dysfunctional organelles and is closed up by the fusion of the two ends of the membrane to form an autophagosome (Fig. 1b). The autophagosome fuses with lysosomes (autolysosome), which results in proteolytic degradation of the inner membrane and trapped contents. Finally, the autolysosome ruptures to release the degraded contents into the cytoplasm. Literature reports are in good agreement that dysfunction of autophagy is likely to contribute significantly to the onset and progression of $\mathrm{AD} .^{\mathbf{4 1}}$ Dysregulation of autophagy impairs neuronal and nutrient homeostasis, which in turn contributes to pathogenic processes in $\mathrm{AD}$. Defects in autophagy occur in the early stage of $\mathrm{AD}$ pathogenesis, and therefore the development of activators of autophagy is an effective strategy for the clearance of toxic peptide or protein aggregates (A $\beta$ and Tau). ${ }^{42}$

\section{Diagnostic intervention}

The timely diagnosis of $\mathrm{AD}$ is the most important requirement and is critical for understanding the severity of the disease condition and providing appropriate treatment to the patient. As was mentioned previously, there are no approved methods for the diagnosis of $\mathrm{AD}$, which in turn affects the design and development of therapeutic modalities. The current diagnosis of $\mathrm{AD}$ is mostly based on the assessment of the behaviour and cognitive state of patients. Cognitive deficits are observed only in the advanced stage of the disease, and irreversible damage 
has already occurred in the brain of the patient. Studies suggest that amyloid deposits and changes symptomatic of the disease possibly develop decades before a noticeable decline in cognitive function. ${ }^{43}$ Therefore, the development of molecular tools and techniques for early diagnosis has been the prime focus of research into $\mathrm{AD}$. In this context, $\mathrm{A} \beta$ peptides, polymorphic aggregated $A \beta$ species, hyperphosphorylated Tau, Tau aggregates, neurogranin, APP and monocyte chemoattractant protein-1 (MCP-1) in the brain, cerebrospinal fluid (CSF) and blood are considered to be potential biomarkers for early diagnosis (Fig. 2). Currently, a great amount of resources and research efforts are directed at the development of molecular tools and techniques for the identification and quantification of these biomarkers. ${ }^{\mathbf{4 4}}$

\subsection{Far-red fluorescent probes}

It is widely accepted that the presence of $A \beta$ plaques precedes the clinical symptoms of AD. Furthermore, the amyloid hypothesis plays a key role in all other disease hypotheses that have been put forward for AD. Therefore, targeting A $\beta$ species as biomarkers is an ideal strategy for developing tools and methods for the early diagnosis of $\mathrm{AD}$ (Fig. 2). Fluorescent probes provide a real-time, non-radioactive, high-resolution and inexpensive imaging technique for detecting $\mathrm{A} \beta$ species in the brain. In particular, far-red fluorescent probes are a special class of probes that are useful for the detection and imaging of $\mathrm{A} \beta$ species and have distinct advantages over normal probes. Red and near-infrared (NIR) molecular probes with emissions in the region of $650-800 \mathrm{~nm}$ are highly sought-after tools owing to their excitation by visible wavelengths, minimal interference from autofluorescence and scattering by biomolecules, and the advantages of a great sample penetration depth and enhanced sensitivity. These important and valuable attributes make them viable probes for developing detection and imaging tools for $\mathrm{AD}$. In recent years, derivatives of oxazine, BODIPY, curcumin, styryl, stilbene, thiophenes and benzothiazole have been developed and extensively used as fluorescent probes for $A \beta$ and Tau aggregates. ${ }^{45-48} \mathrm{~A}$ dual-response probe, namely, benzothiazole-coumarin (TC), was developed by our group for the detection of $\mathrm{A} \beta 42$ aggregates. ${ }^{49}$ TC exhibited turn-on red fluorescence $\left(\lambda_{\mathrm{ex}}=537 \mathrm{~nm}, \lambda_{\mathrm{em}}=654 \mathrm{~nm}\right)$ with a large Stokes shift $(\sim 117 \mathrm{~nm})$ and a characteristic colourimetric response upon binding to $\mathrm{A} \beta 42$ aggregates (Fig. 3a and b). Although the TC probe displayed high sensitivity and specificity towards $A \beta 42$ aggregates over other abnormal protein aggregates, namely, $\alpha$-synuclein ( $\alpha$-Syn, Parkinson's disease) and islet amyloid polypeptide (IAPP, type II diabetes), the probe was found to bind DNA. In the presence of both $A \beta 42$ fibrillar aggregates and DNA, TC preferentially binds to A $\beta 42$ fibrillar aggregates over DNA, which is attributed to the high binding affinity of TC for A $\beta 42$ fibrillar aggregates.

The $\beta$-sheet structure is the common structural conformation observed among most amyloid aggregates, which has hindered the development of probes for the selective and specific detection of any individual protein aggregate. In fact, numerous fluorescent probes have been reported for $A \beta$ aggregates, $A \beta$ polymorphs, Tau aggregates and NFTs. However, most of these probes lack selectivity towards a specific protein aggregate and therefore cannot be developed into diagnostic tools for the detection of AD. This underlines the need for the development of selective probes for specific protein aggregates to accomplish a definitive diagnosis of AD. Hyperphosphorylated Tau and NFTs are signatures of tauopathies (frontotemporal dementia and supranuclear palsy, among others), which involve a breakdown of the normal functionality of Tau protein and are responsible for causing dementia

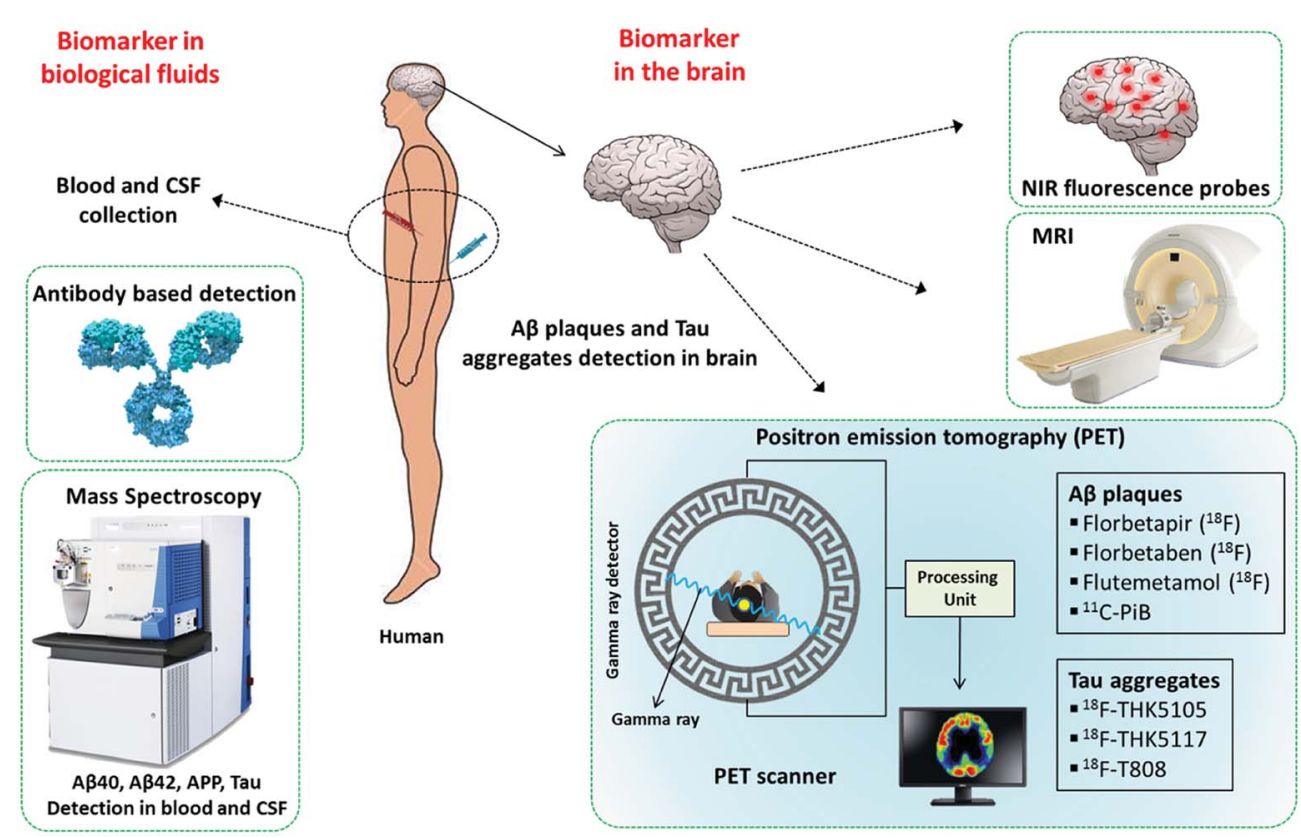

Fig. 2 Molecular tools and techniques available for the detection of biomarkers in AD. 
a)

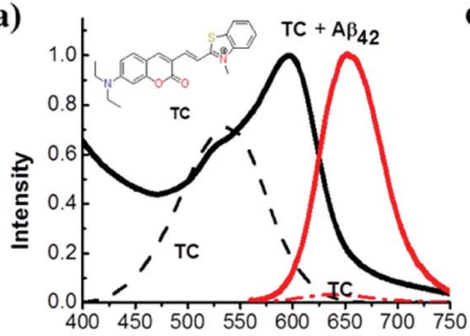

Wavelength $(\mathrm{nm})$

b)

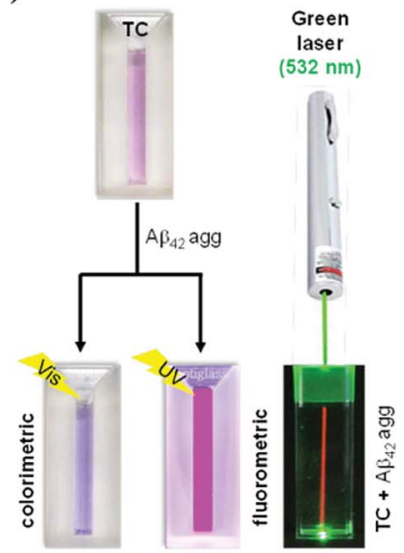

c)

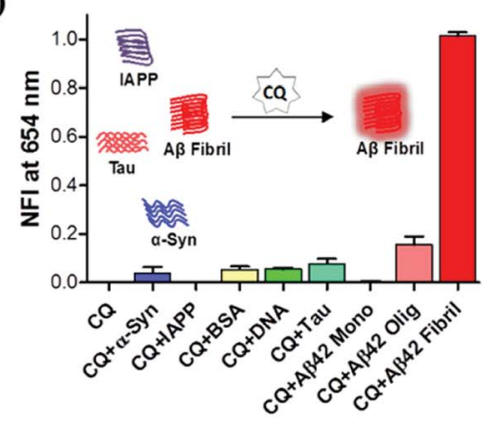

d)
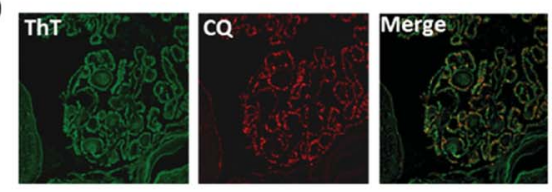

e)

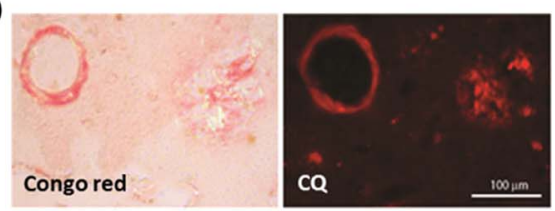

f)
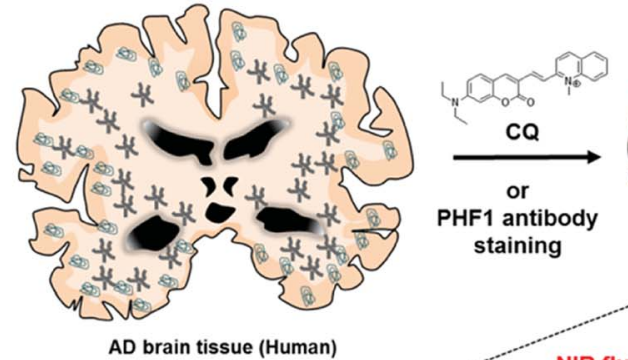

PHF1 antibody

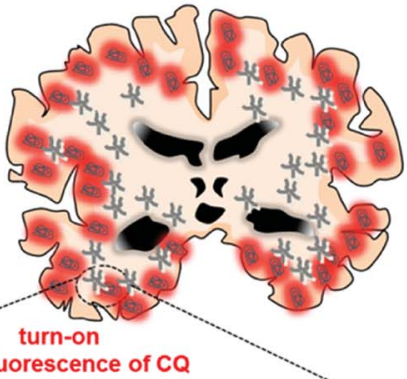

NIR fluorescence of $\mathrm{CQ}$

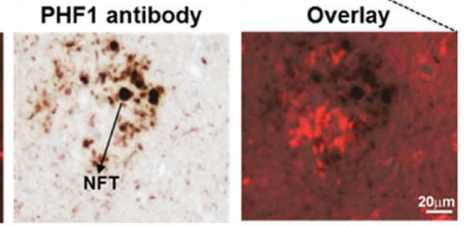

Fig. 3 Red and NIR (far-red) fluorescent probes for diagnosis of AD. (a) Absorption and emission ( $\lambda_{\text {ex }}=537 \mathrm{~nm}$ ) spectra of the probe TC in the presence and absence (dotted lines) of A 42 fibrillar aggregates. Inset: molecular structure of TC. (b) Photographs of TC and samples of TC + A 342 fibrillar aggregates illuminated with visible and UV light ( $365 \mathrm{~nm}$ ) and TC + A 42 fibrillar aggregates illuminated with a green laser ( $532 \mathrm{~nm}$ ), which gives a red beam in the sample solution. (c) Normalized fluorescence intensity (NFI) of CQ upon interaction with various protein aggregates, biomacromolecules and polymorphic A $\beta$ species. (d) Dual staining of human brain cross-sections using CQ and ThT (100 nM CQ: $1.57 \mathrm{mM}$ thioflavin T). (e) $C Q$ stains $A \beta$ plaques and congophilic angiopathy in human brain tissue with Congo red as control. (f) Molecular structure of the probe $C Q$ and selective staining of $A \beta$ plaques in human brain tissue. $C Q$ selectively stains $A \beta$ plaques in brain tissue in $A D$ even in the presence of NFTs of Tau. This figure has been adapted from ref. 49 and 50 with permission from Nature Publishing Group and Elsevier, respectively.

independently of $\mathrm{AD}$. The differential diagnosis of $\mathrm{AD}$ from tauopathies, other neurodegenerative diseases and, in particular, cases of mixed dementia demands the specific detection of $\mathrm{A} \beta$ species. We have developed a unique turn-on NIR fluorescent probe (CQ) by subjecting the TC probe to a rigorous structure-activity study for the detection of $A \beta 42$ aggregates over Tau and other protein aggregates (Fig. 3)..$^{50}$ Coumarinquinoline $\left(\mathbf{C Q}, \lambda_{\mathrm{ex}}=521 \mathrm{~nm}, \lambda_{\mathrm{em}}=654 \mathrm{~nm}\right)$ exhibited remarkable fluorescence enhancement, binding affinity (82 $\mathrm{nM}$ ), quantum yield (0.36) and selectivity towards $A \beta 42$ aggregates. The selectivity of the probe was further confirmed by insignificant interference from the presence of various biomacromolecules (human serum albumin and DNA) and other toxic protein aggregates of Tau, $\alpha$-Syn and IAPP (Fig. 3c). The differential detection of $A \beta 42$ aggregates from Tau and other protein aggregates is vital in the clinical differentiation of $\mathrm{AD}$ from Tau pathology and cases of mixed dementia.

Furthermore, the specificity and sensitivity of $\mathbf{C Q}$ towards $\mathrm{A} \beta$ plaques were assessed in brain tissue from an $\mathrm{AD}$ patient. CQ efficiently stained $A \beta$ plaques with a high signal-to-noise ratio and required a concentration that was lower by a factor of 15700 to stain $A \beta$ plaques in comparison with the control dyes thioflavin T (ThT) and thioflavin S (ThS) (Fig. 3d). Interestingly, various forms of $A \beta$ plaques such as amyloid angiopathy and core/diffuse plaques were observed (Fig. 3e). The specific staining of $A \beta$ plaques in $A D$ brain tissue in the presence of coexisting Tau aggregates/NFTs is a remarkable property that is useful for developing specific tools for the clinical diagnosis of $\mathrm{AD}$ and differentiating it from Tau pathology (Fig. 3f). The utility of NIR probes for the in vitro detection, imaging and monitoring of $A \beta$ aggregates has been quite successful. However, in vivo NIR fluorescence imaging of the human brain is limited by the current scope of fluorescence imaging techniques. This limitation of fluorescent probes for in vivo imaging of the human brain has led to the study of radiolabeling of fluorescent probes for positron emission tomography (PET) and single-photon emission computed tomography (SPECT) imaging, which are well-established techniques for application in humans. The NIR probe CQ, which exhibits good tissue penetration depths and blood-brain barrier (BBB) permeability, is a viable tool for 
academic/medical/disease research, monitoring disease progression, and in cellulo, in vitro (tissues) and in vivo imaging in animal models. The efficient BBB permeability and high sensitivity and selectivity of $\mathbf{C Q}$ towards $\mathrm{A} \beta$ plaques make it an ideal candidate for development as a PET probe, and currently work is in progress in our laboratory.

\subsection{PET and SPECT}

The pathological markers $A \beta$ plaques and NFTs form in the brain decades before cognitive symptoms are manifested in an $\mathrm{AD}$ patient. Therefore, the in vivo imaging of $\mathrm{A} \beta$ plaques or NFTs in the human brain is a current requirement for the early diagnosis of $\mathrm{AD}$ pathology, and $\mathrm{PET}$ is considered to be a potential technique that may serve this purpose (Fig. 2). ${ }^{51}$ In this context, ${ }^{11} \mathrm{C}$-labelled Pittsburgh compound $\mathrm{B}\left({ }^{11} \mathrm{C}-\mathrm{PiB}\right)$, which is a radioactive analogue of ThT, was one of the first tracers used to image $\mathrm{A} \beta$ plaques in the brain. However, ${ }^{11} \mathrm{C}-\mathrm{PiB}$ suffers from the very short half-life of ${ }^{11} \mathrm{C}$ (20.33 min) (Fig. 4). ${ }^{52}$ Flutemetamol $\left({ }^{18} \mathrm{~F}\right)$, which is a derivative of $\mathrm{PiB}$ labelled with ${ }^{18} \mathrm{~F}$, exhibited improved longevity for imaging, which was attributed to the longer half-life of ${ }^{18} \mathrm{~F}$ (109.7 min). Flutemetamol is approved by the FDA for in vivo PET imaging of $\mathrm{A} \beta$ plaques in the brain. Florbetapir $\left({ }^{18} \mathrm{~F}\right)$ and florbetaben $\left({ }^{18} \mathrm{~F}\right)$ are two other PET tracer analogues from the PiB family that are approved for in vivo imaging of amyloid plaques in the brain in AD (Fig. 4). ${ }^{53,54}$ Similarly, several PET probes have been developed for imaging Tau aggregates involved in AD and tauopathies. ${ }^{55}$ However, these probes are not approved for clinical imaging of Tau aggregates in the brain (Fig. 4). The quinolone derivatives ${ }^{18}$ F-THK5105 and ${ }^{18}$ F-THK5117 were developed for imaging Tau aggregates in $\mathrm{AD}$ patients. The retention of these probes was found to be good in regions of Tau deposits in the brain. ${ }^{56,57}$ The benzimidazole derivative ${ }^{18} \mathrm{~F}$-T808 is a PET probe that has been reported for the detection of hyperphosphorylated Tau over other forms of Tau aggregates. Data showed a good kinetic profile and retention time for this probe in the brain, which differentiate $\mathrm{AD}$ patients from healthy controls. ${ }^{58}$ Similarly to PET probes, SPECT probes were also developed to study and detect amyloid aggregates in the brain. ${ }^{59}$ SPECT is more convenient than PET with respect to the number of facilities available and its use of radionuclides with longer half-lives. However, SPECT suffers from lower sensitivity and spatial resolution in comparison with PET imaging. Among the SPECT probes used for imaging amyloid, ${ }^{123}$ I-IMPY has shown

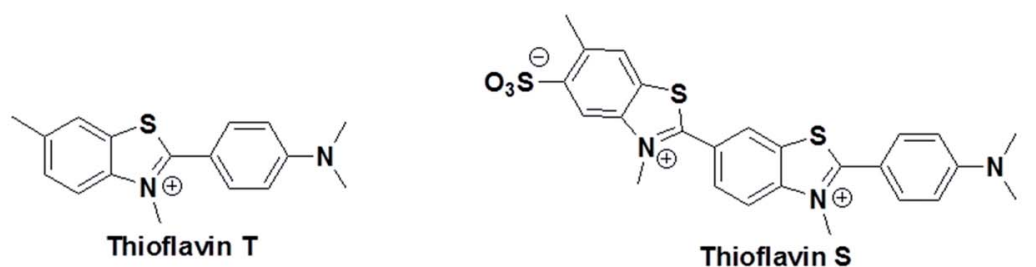<smiles>CNc1ccc(-c2nc3ccc(O)cc3s2)cc1</smiles>

Pittsburgh compound B<smiles>CNc1ccc(/C=C/c2ccc(OCCOCCOCC(F)(F)F)nc2)cc1</smiles><smiles>CNc1ccc(-c2nc3ccc(O)cc3s2)cc1[18F]</smiles><smiles>CCOCCOCCOCCOc1ccc(/C=C/c2ccc(NC)cc2)cc1</smiles><smiles>CN(C)c1ccc(-c2ccc3cc(OCC(O)C[18F])ccc3n2)cc1</smiles><smiles>CNc1ccc(-c2ccc3cc(OCC(O)C[18F])ccc3n2)cc1</smiles>
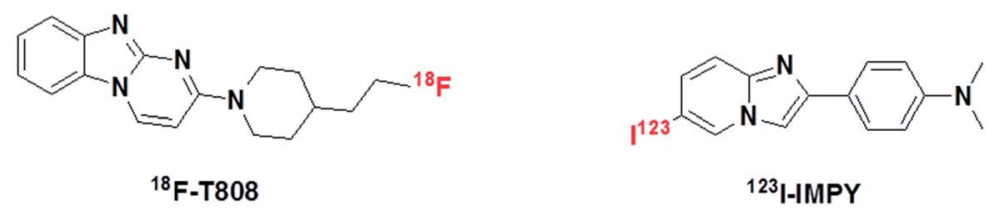

Fig. 4 Molecular structures of thioflavin T, thioflavin S, PET probes and SPECT probe for the detection and imaging of A $\beta$ and Tau aggregates. 
promising results because it preferentially binds to $\mathrm{A} \beta$ plaques in the brain. ${ }^{60}$ Currently, PET-based imaging is the only technique available for the early clinical diagnosis of AD. However, this method involves radioactive tracers and requires expensive and sophisticated instrumentation, and affordability issues have hindered the widespread use of PET imaging for the diagnosis of $\mathrm{AD}$. Moreover, the entire range of PET probes (based on ThT, which is a non-selective probe for the detection and staining of protein aggregates), whether approved or undergoing clinical trials, lack complete selectivity towards their target protein aggregates, which may lead to incorrect diagnosis and treatment. Non-selective staining becomes a severe problem when using PET probes in the case of patients with mixed dementia. Therefore, there is an urgent need to develop selective PET probes for both $A \beta$ plaques and Tau aggregates/NFTs.

\subsection{Magnetic resonance imaging}

Magnetic resonance imaging (MRI) is a non-invasive method for studying both structural and functional features of the brain. ${ }^{61}$ There are two types of MRI techniques, namely, structural imaging (SMRI) and functional imaging (fMRI). SMRI is used to study atrophy of the brain and is not a suitable diagnostic tool for $\mathrm{AD}$. Atrophy that is observed may not be specific to $\mathrm{AD}$ and can be associated with any form of neuronal disorder. This lack of specificity also limits the utility of sMRI for the detection and imaging of histopathological hallmarks of $\mathrm{AD}$ such as senile plaques and NFTs. fMRI is employed to study the functional integrity of the brain, which includes memory formation, cognitive changes over time, and neuronal activity. fMRI studies have shown significant differences in the brain's complex network during aging, mild cognitive impairment (MCI), and AD. Moreover, fMRI revealed changes in functional connectivity during the progression of $\mathrm{AD}$. This suggests that monitoring changes in functional connectivity using fMRI could be a promising biomarker for AD. However, work in this field is at a very early stage and needs to be standardized in multiple patients for the successful application of fMRI as a diagnostic tool for AD. ${ }^{62}$ Nevertheless, combining the power of MRI and PET imaging using selective and sensitive molecular probes may possibly deliver better tools for the early diagnosis of AD.

\subsection{Mass spectrometry}

The detection of biomarkers in the brain is an exceptionally challenging task and demands sophisticated, safe and practically viable techniques. On the other hand, the development and validation of tools and methods for the identification of biomarkers in biological fluids such as blood and CSF is appealing owing to the ease of accessibility of samples and requires the immediate attention of researchers and clinicians. $^{63}$ Numerous techniques, such as ELISA, DNA-based probes, and antibodies, have been reported in the literature for the detection of biomarkers in blood and CSF; however, these techniques suffer from some common as well as specific limitations. ${ }^{64} \mathrm{CSF}$ is a colourless fluid that is produced in the choroid plexus, which fills and circulates in the ventricular system, cisterns, sulci and the central canal of the spinal cord. ${ }^{65}$ It is believed that any biochemical changes and alterations in the levels of biomolecular markers that occur in the brain must be reflected in CSF. As a result, CSF has been used for the detection of $A \beta$ and Tau aggregates and their concentrations for the early diagnosis of AD. Unlike blood, CSF is drawn from the spine by a procedure called lumbar puncture, which is painful and can cause adverse side effects in patients. ${ }^{65}$ Therefore, the use of blood samples for identifying biomarkers has several advantages and has received interest for the diagnosis of $\mathrm{AD} .^{\mathbf{6 6}}$ The concentrations of $A \beta$ species and Tau in blood (plasma and serum) are much lower in comparison with their levels in CSF. This bottleneck necessitates the development of ultrasensitive techniques for the analysis of biomarkers in blood samples. The use of highly sensitive mass spectrometry (MS) for the detection of biomarkers in blood samples is a promising technique. A number of biomolecules, including APP, A $\beta$ species, Tau, pTau, apolipoprotein E (ApoE), interleukins (IL-1 $\alpha$, IL-6), clusterin (CLU) and $\alpha$-1-antichymotrypsin ( $\alpha$-ACT), among others, have been considered as potential biomarkers, and the assessment of their precise concentrations in blood is anticipated to provide a reliable diagnostic method for $\mathrm{AD} .{ }^{67}$ In particular, $\mathrm{A} \beta$ peptides and their concentrations in plasma have been extensively investigated as biomarkers for AD. However, it is unclear to what extent $\mathrm{A} \beta$ levels in blood samples can serve as a precise diagnostic indicator of $\mathrm{AD}$. Several studies have indicated that the mere presence of $A \beta 40$ and $A \beta 42$ in a blood sample is not correlated with pathological conditions in $\mathrm{AD} .{ }^{68}$ The majority of reports have confirmed the fact that the $A \beta 42 / A \beta 40$ concentration ratio in blood samples has greater significance for the diagnosis of $\mathrm{AD}$ in comparison with the quantification of individual species. In a recent study, Yanagisawa et al. used immunoprecipitation coupled with mass spectrometry for the definitive detection of biomarkers in blood that are correlated with amyloid deposits in the brain. ${ }^{69} \mathrm{~A}$ composite parameter was derived from the $\mathrm{APP} / \mathrm{A} \beta 42$ and $\mathrm{A} \beta 40 / \mathrm{A} \beta 42$ ratios to define the $A \beta$-positive or -negative status of the brain, and the results were validated via PET imaging of the brain. In this study two independent datasets were obtained from Japan $(n=121)$ and Australia $(n=252)$, which included normal individuals, individuals with MCI and individuals with AD. Composite biomarker data obtained by blood analysis have been used to determine the $\mathrm{A} \beta$ plaque load in the brain with an accuracy of 90\% and statistical significance. This MS-based technique appears to be promising; however, much more standardization and improvements are needed for its real-world application.

\section{Therapeutic intervention}

AChE inhibitors (Aricept (donepezil), nivalin (galantamine), Rivastach (rivastigmine), Cognex (tacrine)) and a weak antagonist of the NMDA receptor (Namenda (memantine)) are the few drugs approved for the treatment of $\mathrm{AD} .{ }^{27}$ However, these drugs do not act directly on the underlying disease mechanisms and only offer symptomatic and temporary relief in cases of mild to moderate $\mathrm{AD} .{ }^{70}$ In other words, there are no approved drugs that target the core pathology of $\mathrm{AD}$ to slow or prevent the 
progression of the disease. ${ }^{71}$ Moreover, memantine was approved in 2003, and since then no new treatments have been developed for $\mathrm{AD}$. Another cause for concern in the community is that there are absolutely no treatments for advanced stages of $\mathrm{AD}$. Although a large number of drugs have undergone clinical trials, most of them failed (99.6\%) at various stages of the trials. In spite of disappointing failures, there has been appreciable progress in understanding the disease mechanisms and with respect to tangible biomarkers and targets. The lessons and knowledge gained from numerous failures and setbacks will definitely help academic researchers, clinicians and pharmaceutical companies to develop effective and successful drug candidates for $\mathrm{AD}$ in the near future. In fact, a significant number of drug candidates that target various therapeutic pathways in $\mathrm{AD}$ are undergoing preclinical and clinical trials. We discuss drug candidates that target various therapeutic pathways in $\mathrm{AD}$ in the following section, which includes efforts by our own research group to develop multifunctional modulators as drug candidates.

\subsection{Targeting $A \beta$ and Tau aggregation}

The presence of extracellular senile plaques (A $\beta$ peptide) and intracellular NFTs (Tau protein) is a hallmark of AD. Targeting the aggregation process of $A \beta$ and Tau has been an active strategy for the design and development of therapeutic agents for pharmacological intervention in $\mathrm{AD}$. Molecules that can effectively (i) prevent fibrillogenesis or dissolve plaques, (ii) destabilize toxic oligomers, (iii) prevent metal-mediated aggregation or (iv) clear toxic aggregates from the brain are termed as aggregation modulators. This section has been divided into several subsections on the basis of the nature and action of the drug candidate.

4.1.1 Small molecules. The modulation of amyloid aggregation ( $\mathrm{A} \beta$ and $\mathrm{Tau}$ ) by small molecules has been an effective strategy and has met with reasonable success. However, most small-molecule-based aggregation modulators have failed in clinical trials. ${ }^{72}$ This scenario necessitates the careful and comprehensive design of efficient functional drug candidates for targeting amyloid aggregation that takes into account the reasons for failure and missing links in previous approaches. Several synthetic derivatives have been developed and tested as modulators of $A \beta$ or Tau aggregation. ${ }^{73}$ Among these, very few molecules, such as cyclohexane-1,2,3,4,5,6-hexaol (A $\beta$ aggregation) and methylthioninium chloride (LMTM: TRx-0237) (Tau aggregation), have advanced to clinical trials, although the trials were subsequently stopped owing to discouraging results (Fig. 5). ${ }^{74,75}$ In the search for aggregation modulators, natural products have displayed promising results. Natural products such as curcumin, resveratrol and EGCG have been shown to effectively decrease the $A \beta$ plaque load and improve cognition in mice with $\mathrm{AD}$ as a result of their anti-aggregation and antioxidant properties (Fig. 5). ${ }^{76}$ Similarly, brazilin, which is derived from Caesalpinia sappan, inhibits the aggregation of $\mathrm{A} \beta 42$ and prevents the formation of secondary nucleation cores for the further fibrillogenesis of $\mathrm{A} \beta 42$ to form toxic $\mathrm{A} \beta 42$ species. $^{77}$ Tanshinone, which is extracted from beans from Voacanga africana, inhibits the fibrillogenesis of $\mathrm{A} \beta 42$, disrupts preformed $\mathrm{A} \beta 42$ aggregates and ameliorates the neuronal toxicity of $\mathrm{A} \beta .^{78}$ Orcein, which is a natural product extracted from Roccella tinctoria, is an accelerator of the aggregation of $\mathrm{A} \beta 42$. It interacts with the hydrophobic region of toxic $A \beta 42$ oligomers and protofibrils and accelerates the formation of relatively less toxic A $\beta 42$ fibrillar aggregates. ${ }^{79}$ Oleuropein aglycone, which is a phenolic derivative obtained from olives, binds to Tau and prevents its aggregation to form toxic species. ${ }^{80}$ Although small molecules and natural products have shown promising results as aggregation modulators, their effectiveness in clinical trials has yet to be systematically assessed. Moreover, the success of aggregation modulators based on small molecules or natural products depends on the incorporation of additional features that alleviate the multifaceted toxicity of $\mathrm{AD}$.

4.1.2 Peptidomimetics. Peptidomimetics are synthetic analogues of natural peptides or proteins with improved biostability, bioavailability and ability to interact with biological targets to produce similar or superior biological effects. ${ }^{\mathbf{8 1 , 8 2}}$ Design strategies for developing peptidomimetic-based aggregation modulators have mostly relied on targeting the hydrophobic core recognition units of $A \beta$ (KLVFF) and Tau (VQIVYK and VQIINK). ${ }^{83,84}$ The hydrophobic core recognition sequences interact with and inhibit the aggregation of the respective parent peptide or protein. However, weak interactions of the core recognition sequence with the parent peptide or protein and proteolytic instability result in low inhibition efficiency. Attempts to improve the proteolytic stability and binding interactions of natural core recognition sequences led to the development of peptidomimetic inhibitors. Some of the synthetic approaches used to generate peptidomimetics as aggregation modulators include backbone modification, side chain modification, the introduction of specific organic moieties and cyclization. ${ }^{\mathbf{8 1 , 8 5 - 8 7}}$ As has already been suggested, the inhibition of aggregation alone is not sufficient to tackle the multifactorial pathology of AD. Therefore, multifunctional peptidomimetic-based aggregation modulators have been developed, which are capable of targeting other pathophysiological factors involved in $\mathrm{AD}$. We have reported a new class of hybrid cyclic peptoids that were designed to modulate autophagy, which is a natural process for clearing toxic aggregates in AD ${ }^{88}$ A simple, differential cyclization of $N^{\alpha}$-alkyl- and $N^{\alpha}$-acylsubstituted $N$-(2-aminoethyl)glycine derivatives was devised by taking advantage of the rigid and flexible backbone to form sixand twelve-membered products, respectively, via intra- and intermolecular cyclization (Fig. 6a). The synthesised hybrid cyclic peptoids were screened for the modulation of autophagy using a firefly luciferase assay in yeast, in which the degradation of a cargo marker (GFP-tagged) was an indicator of autophagy activity. Among the cyclic peptoids that were screened, 4benzylpiperazin-2-one (4a) gave rise to an increase in the rate of degradation of the protein marker via autophagy in a dosedependent manner (Fig. 6b). Furthermore, modifications of $4 \mathbf{a}$ in terms of the structure-activity relationship (SAR) are currently in progress to develop effective modulators of autophagy that target the pathology of AD. 
<smiles>COc1cc(/C=C/C(=O)CC(=O)/C=C/c2ccc(O)c(OC)c2)ccc1O</smiles>

Cyclohexane-1,2,3,4,5,6-hexol<smiles>CN(C)c1ccc2nc3ccc(=[N+](C)C)cc-3sc2c1</smiles>

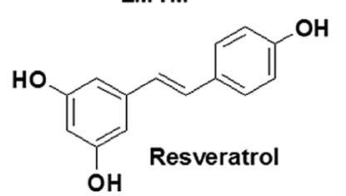

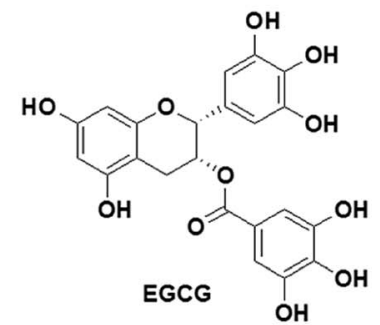

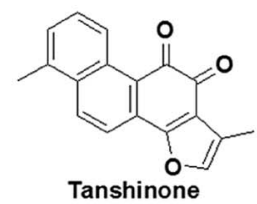

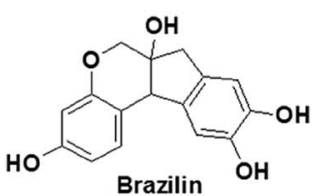<smiles>O=c1cc2oc3cc(O)c(-c4ccc(O)cc4O)cc3nc-2cc1-c1ccc(O)cc1O</smiles><smiles>COC(=O)C1=CO[C@H](O)/C(=C\COC(=O)O[Na])[C@H]1CC(=O)OCCc1ccc(O)c(O)c1</smiles>

Fig. 5 Aggregation inhibitors based on small molecules and natural products.

In a similar strategy, linear peptidomimetic modulators were designed, and the hybrid peptoid P5 was identified as a potential modulator of the aggregation of $A \beta$ and promoted the clearance of toxic $\mathrm{A} \beta$ aggregates by activating autophagy in a yeast model of AD (Fig. 6c) ${ }^{89}$ The design of these peptidomimetics was based on the recognition unit of $A \beta$ peptide (KLVFFA), which interferes with hydrogen bonding and other non-covalent interactions that are responsible for the aggregation $\mathrm{A} \beta$. The peptidomimetics that were designed contain $\mathrm{N}$ terminal thymine/barbiturate and sarcosine ( $N$-methylglycine) at alternate amino acid positions in KLVFFA to target intramolecular and intermolecular hydrogen bonds involved in the aggregation of A $\beta$. The hybrid peptoid P5 with an $\mathrm{N}$-terminal thymine unit and sarcosine at alternate positions effectively inhibited the aggregation of $A \beta$ and dissolved preformed $A \beta 42$ aggregates (Fig. 6d). Furthermore, P5 exhibited high proteolytic and serum stability in comparison with the unmodified peptide (KLVFFA). Interestingly, P5 rescued yeast cells affected by the toxicity of $\mathrm{A} \beta$ by preventing aggregation or dissolving preformed aggregates and in the process promoted their clearance via the autophagy pathway (Fig. 6e and f). In other words, P5 exhibited no rescue effect in autophagy-defective mutant ( $\Delta$ atg1 mutant) yeast cells, which confirms the autophagy-dependent rescue of cells from the toxicity of $A \beta$. This is the first study that successfully employed a peptidomimetic/peptoid modulator to activate autophagy and promote the clearance of toxic $\mathrm{A} \beta$ aggregates from cells. ${ }^{90}$ Although there have been many reports on the modification of recognition units to develop aggregation modulators, few of these were equipped with the multifunctional ability to alleviate the multifaceted toxicity of AD.91-94

According to the metal ion hypothesis, the complexation of redox-active metal ions such as $\mathrm{Cu}^{2+}$ with $\mathrm{A} \beta$ peptide or their inclusion in amyloid aggregates accelerates the toxicity of $\mathrm{A} \beta .^{25,95}$ Therefore, the design of peptide- or peptidomimeticbased metal chelators/sequestrators has been an active area of research, although most of the reported chelators lack multifunctional features. ${ }^{96,97}$ We developed the multifunctional peptidomimetic P6 by conjugating the copper-chelating natural tripeptide Gly-His-Lys (GHK) found in humans and the peptoid- based $A \beta$ aggregation modulator P5 (Fig. 7a and b). ${ }^{98}$ The A $\beta 42 /$ $\mathrm{Cu}^{2+}$ complex has an association constant $\left(K_{\mathrm{a}}\right)$ of $\sim 10^{9}$ to $10^{12}$, and hence a metal chelator with a $K_{\mathrm{a}}$ value of $>10^{9}$ is required to sequester $\mathrm{Cu}^{2+}$ from the $\mathrm{A} \beta-\mathrm{Cu}^{2+}$ complex. GHK has a $K_{\mathrm{a}}$ value of $\sim 10^{14}$, and therefore it can easily sequester the metal ion from the $\mathrm{A} \beta-\mathrm{Cu}^{2+}$ complex. Notably, GHK is incapable of sequestering $\mathrm{Cu}^{2+}$ from biologically relevant metalloprotein complexes $\left(K_{\mathrm{a}}\right.$ of $\sim 10^{15}$ to $10^{17}$ ), which makes GHK an ideal candidate for sequestering $\mathrm{Cu}^{2+}$ from the $\mathrm{A} \beta-\mathrm{Cu}^{2+}$ complex without interfering with the activity of copper-based metalloenzymes. P6 effectively inhibits the formation of toxic $\mathrm{A} \beta$ oligomeric species and fibrillar aggregates. The GHK unit in $\mathbf{P 6}$ retains the ability to chelate $\mathrm{Cu}^{\mathrm{II}}$, and as a result $\mathbf{P 6}$ effectively sequesters $\mathrm{Cu}^{\mathrm{II}}$ from the $\mathrm{A} \beta 42-\mathrm{Cu}^{2+}$ complex and maintains it in a redoxdormant state. $\mathrm{A} \beta 42-\mathrm{Cu}^{\mathrm{II}}$ in a reducing environment is known to generate excess ROS via the redox cycling of $\mathrm{Cu}^{\mathrm{II}}$, and elevated levels of ROS damage biomacromolecules, which contributes to additional cellular toxicity. Data from an in vitro assay to assess A $\beta 42-\mathrm{Cu}^{\mathrm{II}}$-induced DNA damage showed that P6 efficiently sequestered $\mathrm{Cu}^{\mathrm{II}}$ from $\mathrm{A} \beta 42-\mathrm{Cu}^{\mathrm{II}}$ and protected DNA from ROSmediated damage (Fig. 7c). The multifunctional ability of $\mathbf{P 6}$ to inhibit the multifaceted toxicity of $A \beta$ was studied in PC12 cells (Fig. 7d). Cells were rescued from $\mathrm{A} \beta 42-\mathrm{Cu}^{\mathrm{II}}$-induced toxicity, and the amount of ROS that was generated was substantially reduced. The sequestration of the metal, moderation of the aggregation of $\mathrm{A} \beta$ and generation of ROS, protection of DNA, and antioxidant property to prevent oxidative stress make P6 a multifunctional inhibitor of the multifaceted toxicity of $A \beta$. Although the multifunctional ability of peptides and peptidomimetics to modulate the multifaceted toxicity of $A \beta$ is promising, their probable limitations, including blood-brain barrier (BBB) permeability, size and overall stability, could hamper their potential applications for the treatment of AD. Moreover, the modulatory efficacies of small molecules are far superior in comparison with those of peptidomimetics, and as a result none of the peptidomimetics has reached clinical trials. Notwithstanding their limitations, the design and study of peptidomimetics have huge implications for understanding the mechanism of amyloid aggregation (amyloid hypothesis) and 
a)

b)

e)
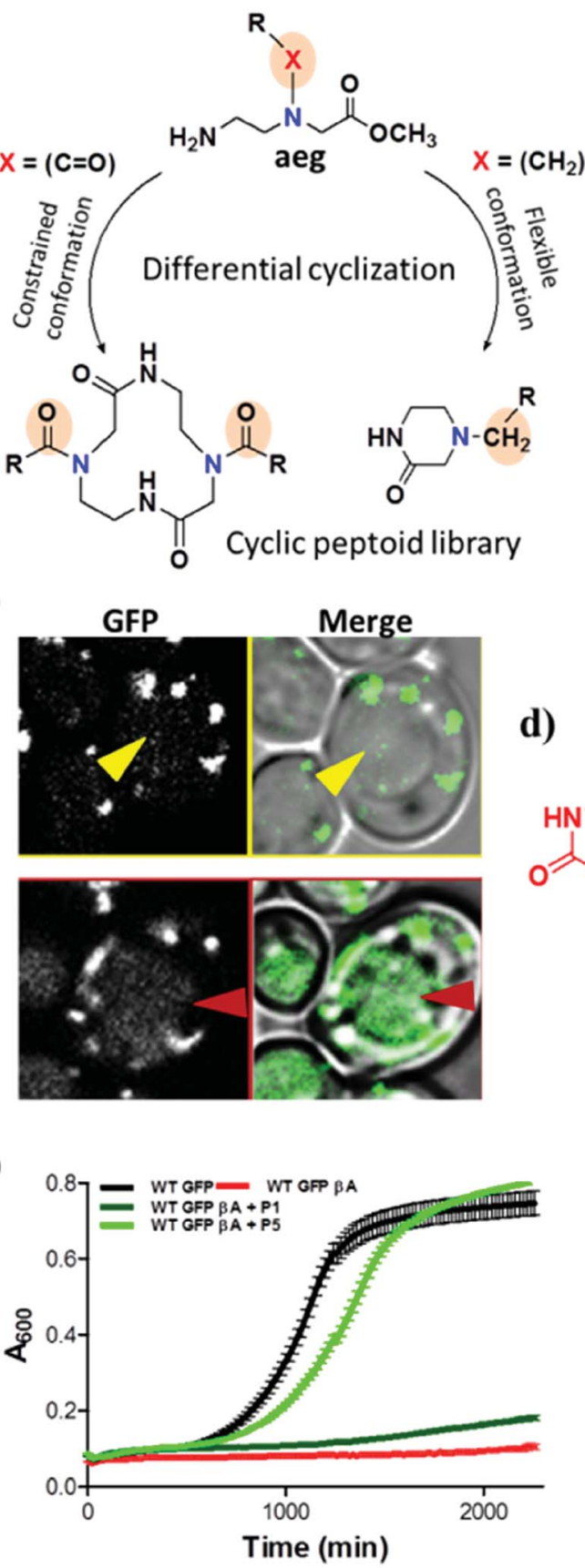

d) c)

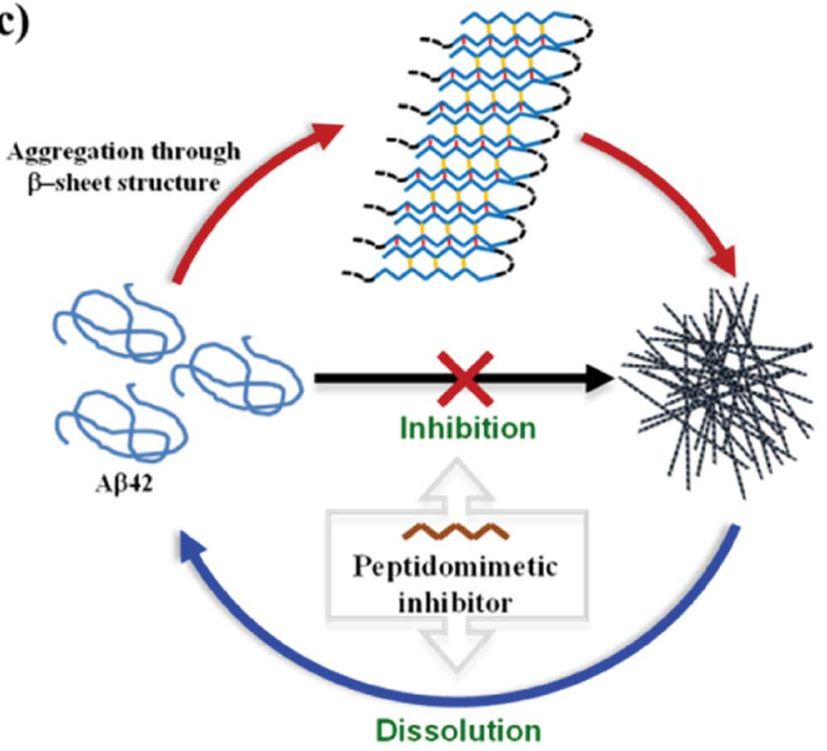<smiles>Cc1cn(CC(=O)N[C@@H](CCCCN)C(=O)N(C)CC(=O)N[C@H](C(=O)N(C)CC(=O)N[C@@H](Cc2ccccc2)C(=O)N(C)CC(N)=O)C(C)C)c(=O)[nH]c1=O</smiles>

f)
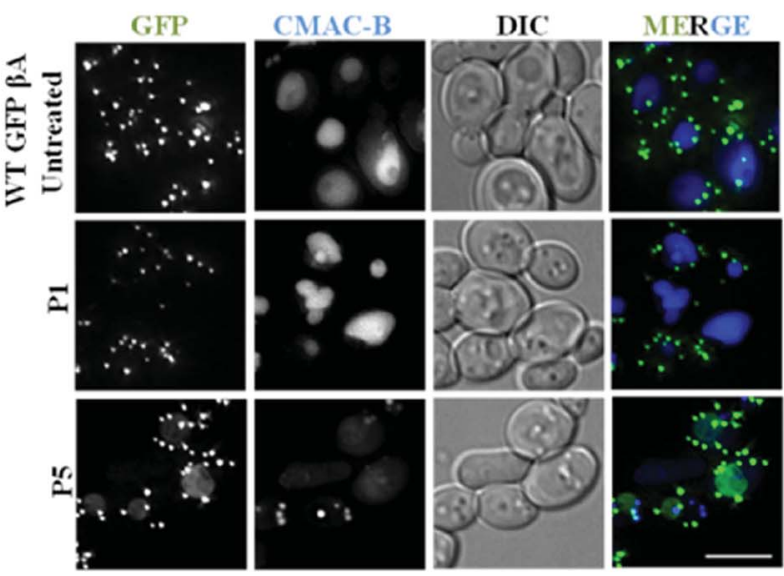

Fig. 6 Peptidomimetic modulators. Cyclic hybrid peptoids (a) as autophagy modulators (b). (c) Schematic representation of inhibition and dissolution of A 342 aggregates by the peptidomimetic inhibitor P5. (d) Structure of P5. (e) Growth curve of yeast (autophagy model) with A $\beta$ toxicity. P5 rescues yeast cells from A $\beta$ toxicity. (f) Degradation of toxic GFP- $\beta$ A by P5 in a WT GFP- $\beta$ A yeast model. This figure has been adapted from ref. 88 and 89 with permission from Wiley and Nature Publishing Group, respectively.

its relation to other hypotheses, which in turn may assist the development of selective and efficient disease-modifying therapeutics for AD.

4.1.3 Metal chelators. $\mathrm{A} \beta$-metal $(\mathrm{Cu}, \mathrm{Fe}$ and $\mathrm{Zn})$ complexation and the related toxicity is at the core of the metal ion hypothesis. $^{24,27}$ The disruption of $\mathrm{A} \beta$-metal interactions using suitably designed metal chelators has been an active area of research. In recent years, extensive research into the development of metal chelators that target $\mathrm{Cu}^{\mathrm{II}}$ in the $\mathrm{A} \beta-\mathrm{Cu}^{\mathrm{II}}$ complex has been undertaken to modulate metal-induced toxicity. ${ }^{99}$ Several metal chelators have been reported to exhibit promising activity in both in vitro and in vivo studies. Among these, the 8hydroxyquinoline analogues clioquinol (Clq) and PBT2 have reached clinical trials (Fig. 7a). In fact, Clq was the first metal chelator to receive approval for clinical trials, but unfortunately failed owing to extreme toxicity. ${ }^{100}$ The second-generation analogue PBT2 displayed promising results in comparison with Clq, although it failed in phase 2 clinical trials (Fig. 8a). ${ }^{101}$ 
a)
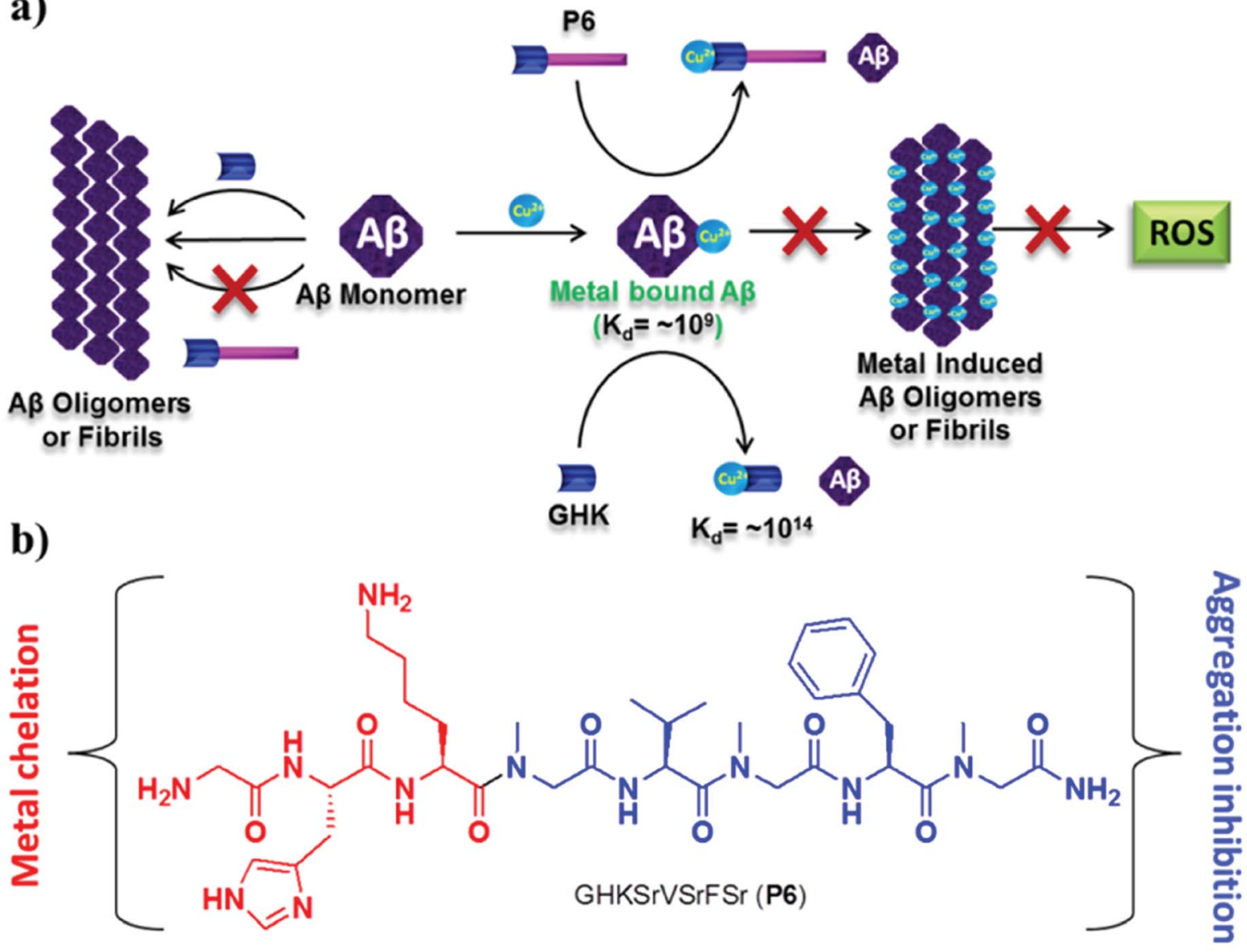

c)

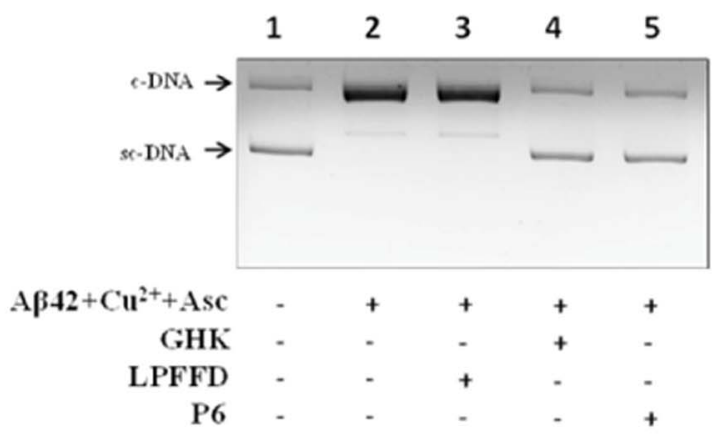

d)

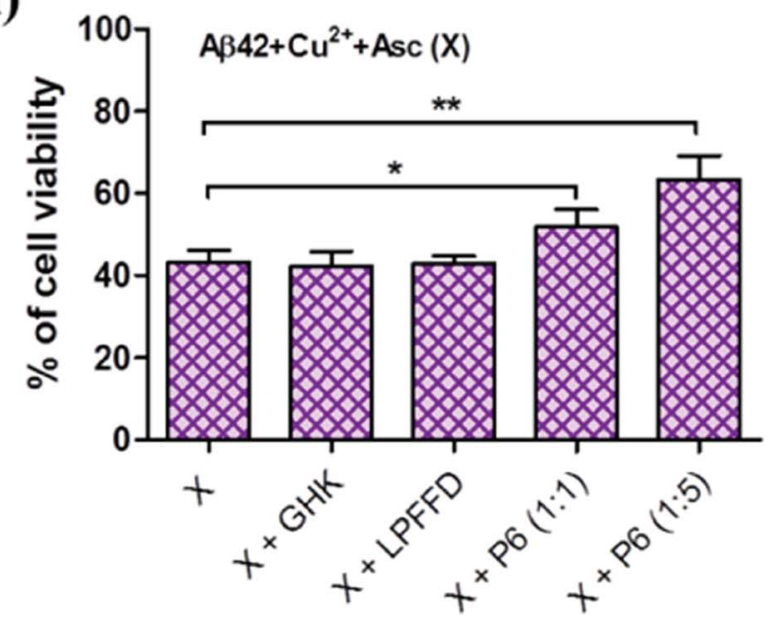

Fig. 7 Multifunctional peptidomimetic modulators. (a) Schematic representation showing modulation of the multifaceted toxicity of A $\beta$ by the multifunctional modulator P6. (b) Molecular structure of P6. (c) P6 rescues plasmid DNA (pBR322) from damage by ROS generated by the A $342+$ $\mathrm{Cu}^{\prime \prime}+$ Asc system. (d) P6 rescues PC12 cells from toxicity induced by metal-induced A 342 aggregates. This figure has been adapted from ref. 98 with permission from the American Chemical Society.

Despite these failures, $\mathrm{Clq}$ and its derivatives continue to inspire the next generation of metal chelators for modulating the toxicity of $\mathrm{A} \beta-\mathrm{Cu}^{\mathrm{II}} \cdot{ }^{102-104}$ In recent years, the design of multifunctional metal chelators has received enormous interest for targeting the multifactorial toxicity found in $\mathrm{AD}$. We designed hybrid multifunctional modulators (HMMs) by the integration of structural (hydroxyquinoline and polyphenolic moieties) and functional features (metal chelation and antioxidant properties) of Clq and EGCG, respectively (Fig. 8). ${ }^{105}$ The lead HMM, namely, TGR86, effectively modulated both metal- 
a)<smiles>Oc1cccc2cccnc12</smiles>

8-Hydroxyquinoline

b)

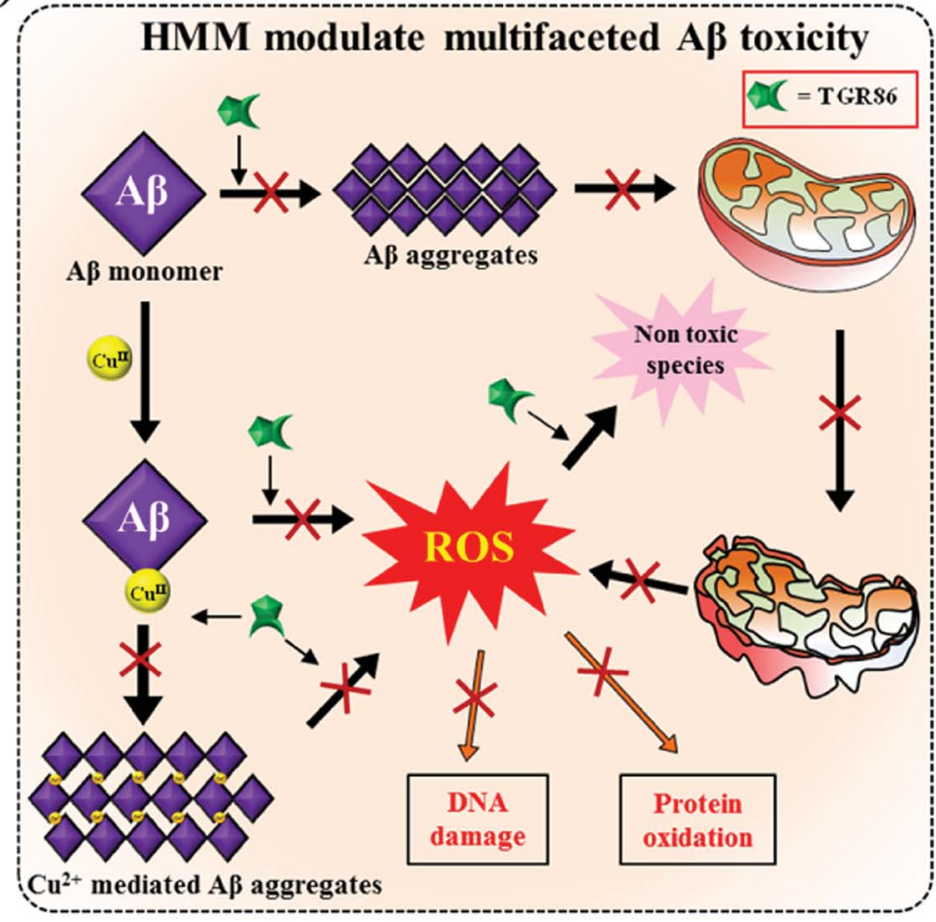

e)

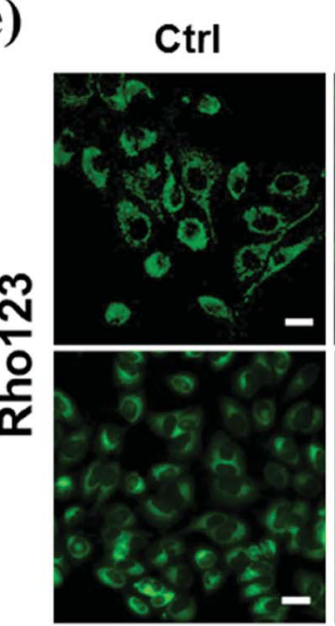

TGR86

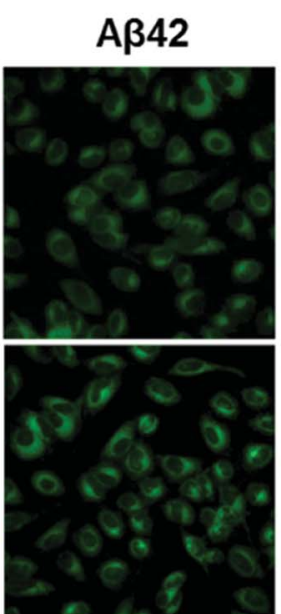

TGR87

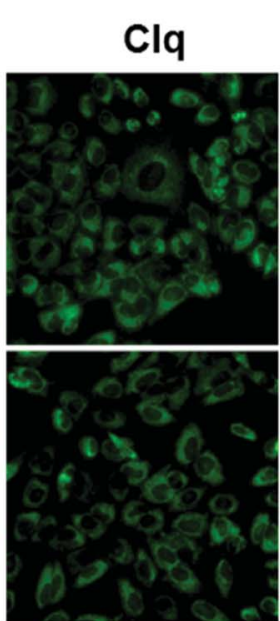

TGR 88 f)

d)<smiles>CN(C)Cc1ccc2c(Cl)cc(Cl)c(O)c2n1</smiles>

PBT2

c)
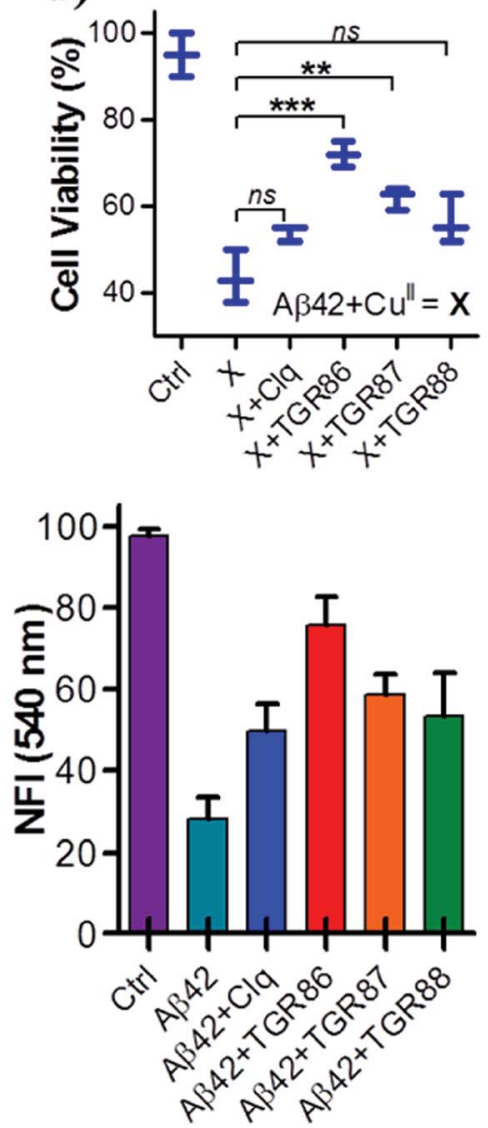

Fig. 8 (a) Small-molecule-based metal chelators and hybrid multifunctional modulators (HMMs). (b) Schematic representation of inhibition of the multifaceted toxicity of $A \beta$ and mitochondrial damage by an HMM. (c) Molecular structure of an HMM (TGR 86). (d) TGR86 rescues PC12 cells from toxicity induced by metal-induced A 342 aggregates. TGR86 rescues the mitochondrial membrane potential of PC12 cells from the metalinduced toxicity of A $\beta 42$. (e) Microscopic images and (f) quantification of fluorescence at $540 \mathrm{~nm}\left(\lambda_{\text {ex }}=511 \mathrm{~nm}\right)$. This figure has been adapted from ref. 105 with permission from the American Chemical Society. 
dependent and -independent aggregation of A $\beta$. A computational study revealed that TGR86 interacts with the loop region of $\mathrm{A} \beta 42$ in the aggregate state via multiple hydrogen-bonding and $\pi$-alkyl interactions. The enhanced modulation of the aggregation of $\mathrm{A} \beta 42$ by TGR86 is also attributed to disruption of the formation of a salt bridge (Lys28-Asp23), as revealed by the computational study. TGR86 exhibits strong affinity for $\mathrm{Cu}^{\mathrm{II}}$ and hence sequesters it from the $\mathrm{A} \beta-\mathrm{Cu}^{\mathrm{II}}$ complex and maintains it in a redox-dormant state, which prevents the redox cycling process responsible for the generation of excess ROS. Unlike highly cytotoxic Clq, the lead HMM TGR86 enabled high cell viability. In cellulo studies of the effect of TGR86 against the toxicity of $\mathrm{A} \beta 42-\mathrm{Cu}^{\mathrm{II}}$ in $\mathrm{PC} 12$ cells showed a significant improvement in cell viability (Fig. 8d). It has been reported in the literature that $A \beta$ interacts with import channels present in the outer mitochondrial membrane, which leads to a decrease in the mitochondrial membrane potential (MMP) and elevated levels of oxidative stress. ${ }^{30,106}$ Mitochondrial membrane damage and dysfunction are also considered to be among the hallmarks of the toxicity of $\mathrm{A} \beta$ observed in $\mathrm{AD}$. Thus, the prevention of mitochondrial damage and the generation of ROS is of immense interest in modulating the pathology of $\mathrm{AD} .^{\mathbf{1 0 7}}$ Evidently, cellular studies of TGR86 showed a significant improvement in the MMP in comparison with neuronal cells treated with $A \beta$ alone (Fig. 8e and f). TGR86 binds toxic A $\beta 42$ and prevents its interaction with the mitochondrial membrane, which is confirmed by the improvements in the membrane potential and cell viability. ${ }^{\mathbf{1 0 8}}$ The development of multifunctional metal chelators is at an early stage, and more dedicated efforts are required to produce efficient and viable nextgeneration drug candidates to target the multifaceted toxicity of $\mathrm{A} \beta$.

4.1.4 Immunotherapy. Immunotherapy is the manipulation of the immune system to elicit the necessary immune response for the treatment of disease. ${ }^{109}$ The concept of immunotherapy has received strong interest from researchers, clinicians and pharmaceutical companies for the development of an effective treatment for AD. Several immunotherapies have been developed and tested in clinical studies aimed at countering the pathology of amyloid or Tau. Immunotherapy in AD can be broadly divided into two major categories: (i) active immunisation ( $\mathrm{A} \beta$ or Tau is administered to patients as an antigen) and (ii) passive immunisation (antibodies against $A \beta$ or Tau are administered to the patient) (Fig. 9a). Antibodies are expected to clear amyloid deposits in the brain by binding to plasma $A \beta$ and promoting its clearance from the blood, which further creates a gradient effect and ultimately causes the clearance of $A \beta$ from the brain. Alternatively, antibodies can bind to deposits of $A \beta$ or Tau and activate macrophages, which in turn affect the clearance of aggregates of $A \beta$ or Tau from the brain. ${ }^{110}$ Currently, immunotherapy has gained considerable importance over other therapeutic strategies; in particular, targeting amyloid aggregates ( $\mathrm{A} \beta$ and Tau) has been found to be a promising approach. In fact, most of the notable players in this area are pharmaceutical companies, which signifies the importance of the amyloid hypothesis and amyloid aggregates as drug targets for the development of disease-modifying therapies for the pathology of $\mathrm{AD}$. The relatively large size, biostability, ineffective crossing of the $\mathrm{BBB}$, undesired immunogenic response and high cost of antigens/antibodies are some of the key factors that need to be considered when developing an effective immunotherapy for $\mathrm{AD}$.

4.1.4.1 Active immunotherapy. Peptide-based vaccines have been designed on the basis of sequences derived from $\mathrm{A} \beta$ and Tau for active immunisation (Fig. 9). In the selection of peptides, sequences responsible for the activation of T-cells were avoided and only fragments responsible for the generation of specific antibodies were considered. Nicolau et al. developed a liposome-based vaccine (ACI-24, phase 1 clinical trials) to generate antibodies against $A \beta$ aggregates without causing activation of inflammatory T-cells. ${ }^{\mathbf{1 1 1}}$ The N-terminal fragment of $A \beta\left(A \beta_{1-15}\right)$ is devoid of $\mathrm{T}$-cell epitopes and prevents the activation of T-cells. In the design of peptide vaccines, $A \beta_{1-15}$ was modified with palmitoylated lysine linkers on both the N-terminus and the C-terminus, and this synthetic modification helped to anchor $\mathrm{A} \beta_{1-15}$ to a liposome (Fig. 9b). $\mathrm{A} \beta_{1-15}$ when immobilized on a liposomal membrane adopts a $\beta$ sheet structure, which acts as an epitope and rapidly stimulates the generation of anti-A $\beta$ antibodies. These antibodies have been shown to dissolve amyloid aggregates in mice with $\mathrm{AD}$ (APPxPS-1). Similarly, a liposome-based vaccine for targeting defined pathological conformers of phosphorylated Tau (ACI35 , phase 1 trials) was developed. ${ }^{112}$ This vaccine comprised a synthetic phosphorylated Tau fragment (16 copies) anchored to a lipid bilayer. Long-term vaccination with ACI-35 in a mouse model of AD improved the clinical condition and reduced tauopathy in the brain without initiating neuroinflammation.

ABvac40 (Araclon Biotech) is the first active vaccine developed to target the C-terminus of $\mathrm{A} \beta 40$ and is undergoing phase 2 clinical trials. ${ }^{113}$ Patients who were treated with ABvac40 generated antibodies against $A \beta 40$ without any significant side effects. AADvac- 1 is another active vaccine developed to provoke an immune response against pathological Tau and is undergoing phase 3 trials. It consists of a peptide derived from Tau (KDNIKHVPGGGS) coupled to keyhole limpet hemocyanin. ${ }^{\mathbf{1 1 4}}$ Vaccination with AADvac-1 induced an active immune response with the production of antibodies capable of discriminating pathological and physiological Tau. A significant reduction in the formation of neurotoxic Tau oligomers and the hyperphosphorylation of Tau ( $95 \%)$ in the brain was reported. CAD106 (Novartis Pharmaceuticals, phase 2 trials) is a virusparticle-based active vaccine that was prepared by coupling multiple copies of the $A \beta_{1-6}$ peptide fragment to a $Q \beta$ virus-like particle. ${ }^{115}$ In models of $\mathrm{AD}, \mathrm{CAD} 106$ induced anti-A $\beta$ antibodies without activating T-cells, which prevented an unwanted inflammatory response. The administration of CAD106 to APP transgenic mice caused a significant reduction in the accumulation of $\mathrm{A} \beta$, and there was no evidence of an increase in microhemorrhages or inflammatory reactions. LuAF20513 (phase 1 trials) is an active vaccine that contains three alternating repeats of an $\mathrm{A} \beta$ peptide fragment $\left(\mathrm{A} \beta_{1-12}\right)$ with sequences from tetanus toxin. ${ }^{\mathbf{1 1 6}}$ This engineered mixed-peptide antigen induces the production of anti-A $\beta$ antibodies that reduce the pathology of $\mathrm{AD}$ without inducing microglial 
a)

Passive immunisation
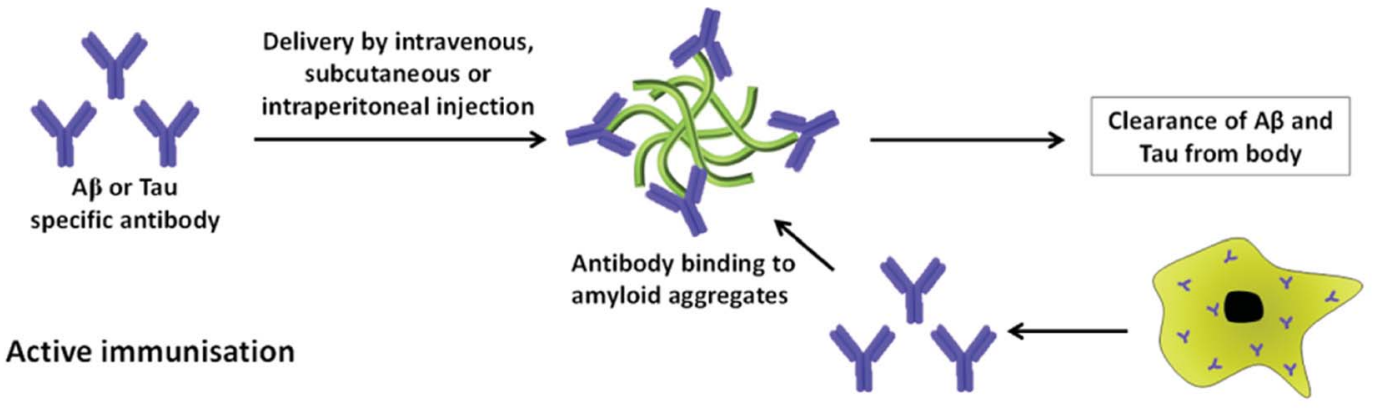

Active immunisation

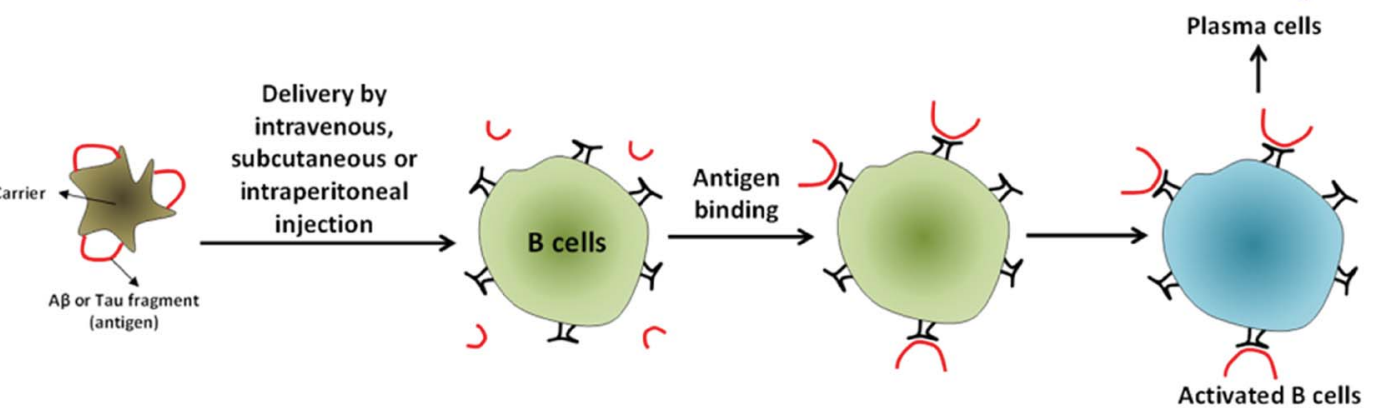

b)

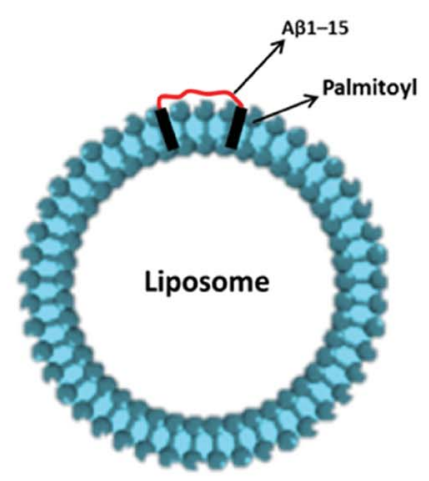

ACl-24

[K(Palm)K(Palm)-Aß1-15 K(Palm)K(Palm)]

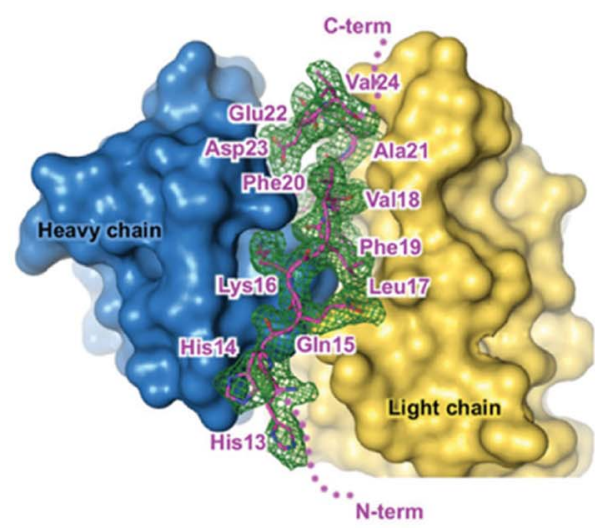

Crenezumab (CreneFab) binding to $A \beta_{11-25}$

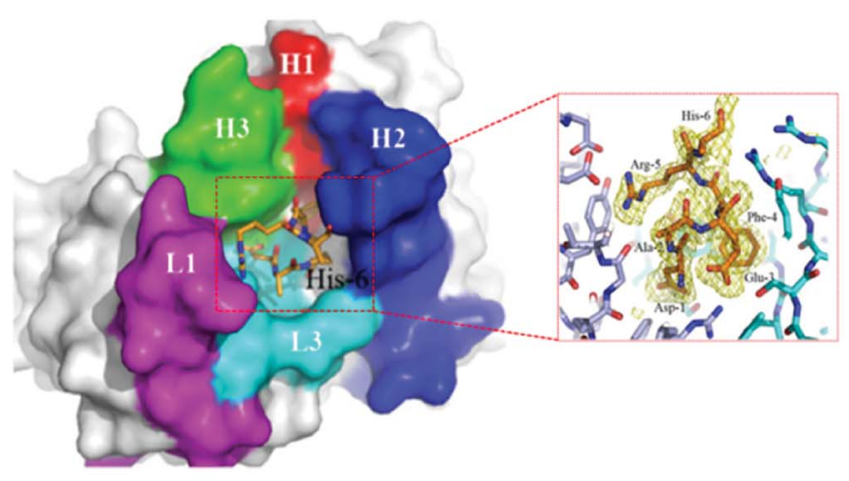

Bapineuzumab (3D6) binding with $A \beta 1-7$

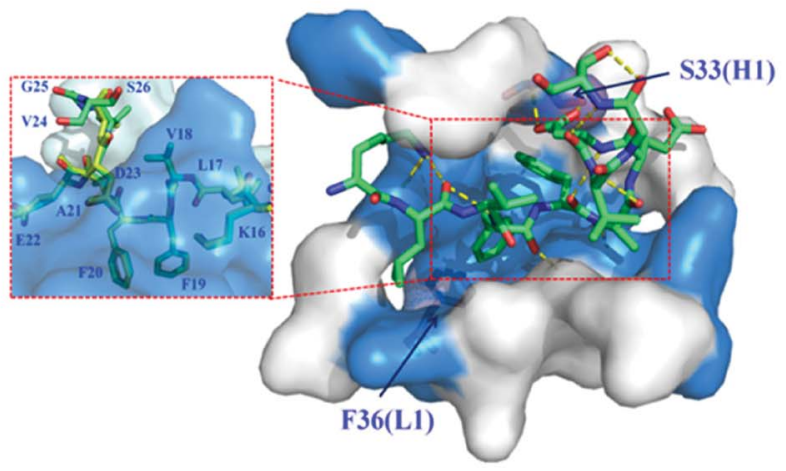

Solanezumab-A $\beta$ complex crystal structure

Fig. 9 (a) Active and passive immunotherapy. (b) Liposome-based active immunisation and interaction of anti-A $\beta$ antibodies with $A \beta$. This figure has been adapted from ref. 120, 123 and 124 with permission from Nature Publishing Group (120 and 124) and BioMed Central (123).

activation in a model of $\mathrm{AD}$. Another distinct and alternative approach to active immunisation involves a DNA-based vaccine, whereby DNA that encodes $A \beta$ peptide is injected into a patient.
DNA is translated to produce $A \beta$ peptide, which subsequently triggers an immune response to generate an $A \beta$-specific antibody. ${ }^{117}$ Although DNA-based immunisation is an interesting 
strategy, this approach is in the early stages of development and has not yet reached clinical trials.

4.1.4.2 Passive immunotherapy. Humanised anti-A $\beta$ antibodies are administered in passive immunisation therapy (Fig. 9). Aducanumab (Biogen, phase 3 trials) is a human monoclonal antibody used against $A \beta$ aggregates. In mice with $\mathrm{AD}$, aducanumab was found to cross the $\mathrm{BBB}$ and preferentially binds to parenchymal over vascular amyloid aggregates. ${ }^{118}$ Aducanumab reduces soluble and insoluble $A \beta$ aggregates in a dose-dependent manner in the brain in AD. Crenezumab (Genentech, phase 3 trials) is a humanised monoclonal antibody developed to recognise polymorphic forms of $A \beta$ aggregates such as oligomers, fibrils and amyloid plaques with high affinity over $\mathrm{A} \beta$ monomer (Fig. 9b). ${ }^{119,120}$ This binding interaction of the antibody promotes the clearance of neurotoxic $\mathrm{A} \beta$ aggregate species from the brain, with limited effects on microglia, which prevents the unwanted release of inflammatory cytokines and thus avoids side effects. Similarly, gantenerumab (Chugai Pharmaceutical), which is a human antibody that specifically binds to $A \beta$ fibrils, is undergoing phase 3 trials. ${ }^{121}$ This antibody binds to $A \beta$ amyloid plaques, attracts microglia and activates phagocytosis. Interestingly, gantenerumab interacts with both parenchymal and vascular $\mathrm{A} \beta$ aggregates. In transgenic mice with $\mathrm{AD}$ (APP/PS-1), gantenerumab was found to bind $A \beta$ and dissolve plaques by recruiting microglia and prevents the formation of newer plaques without altering plasma A $\beta$. BAN2401 (Biogen) is a monoclonal antibody that is currently undergoing phase 2 clinical trials and selectively binds to soluble $A \beta$ protofibrils, which promotes their clearance and the neutralisation of toxic species. ${ }^{122}$ Bapineuzumab (Pfizer) is a humanised form of a murine monoclonal antibody (3D6) that targets the N-terminal region of $\mathrm{A} \beta$ (Fig. 9b). ${ }^{123}$ Bapineuzumab initially showed promising results and reached clinical trials; however, it failed in advanced clinical trials. Solanezumab (Eli Lilly, phase 3 trials) is a humanised monoclonal antibody developed against an $\mathrm{A} \beta$ peptide fragment $\left(A \beta_{13-28}\right)$ (Fig. 9b). ${ }^{124}$ It recognises $A \beta$ monomeric species and not fibrillar aggregates. Solanezumab has shown promising results in phase 2 clinical trials; however, in phase 3 trials it failed to prevent cognitive decline in patients with mild AD. The passive immunisation strategy has been promising, although the low BBB permeability, autoimmune response and inefficient retention of antibodies in the brain have hindered the potential application of drugs to treat $\mathrm{AD}$.

BIIB092 (Biogen, phase 2 trials) is a humanised anti-Tau monoclonal antibody raised against extracellular $\mathrm{N}$-terminally fragmented truncated forms of Tau (eTau), which have been found to cause neuronal hyperactivity and an increase in the production of $\mathrm{A} \beta .{ }^{125} \mathrm{BIIB} 092$ was found to promote the clearance of Tau aggregates from the brain. Similarly, C2N 8E12 is another humanised antibody developed to recognise extracellular pathological Tau aggregates. ${ }^{126}$ Extracellular Tau has been implicated in the transneuronal propagation of Tau in models of AD. The antibody C2N 8E12 has successfully completed phase 1 clinical trials, and phase 2 trials are in progress. In general, the outcomes of the ongoing and planned clinical trials will show whether immunotherapy that targets $A \beta$ and Tau can prevent or delay the pathology of AD.

\subsection{Targeting protein-processing enzymes}

The generation of toxic $A \beta$ and pTau is mediated by various processing enzymes. For example, the processing of APP by the successive proteolytic action of $\beta$-secretase and $\gamma$-secretase releases toxic $A \beta$ peptide. Tau protein bound to microtubules is hyperphosphorylated by the enzymes (kinases) GSK3 $\beta$ and Cdk5, which leads to the abrupt release of pTau and collapse of the microtubules. Thus, therapeutic candidates that target the activity of such processing enzymes have shown significant improvements in slowing the pathology of AD.

4.2.1 $\beta$-Secretase inhibitors. CNP520 is an oral drug candidate that inhibits the proteolytic activity of $\beta$-secretase on APP and reduces the production of A $\beta .{ }^{127}$ Tolerability, pharmacokinetics and pharmacodynamics data are encouraging, and CNP520 is currently undergoing phase 2 clinical trials. Similarly, elenbecestat, JNJ-54861911 and LY3202626 are dihydrothiazine-based $\beta$-secretase inhibitors that efficiently cross the BBB and displayed a dose-dependent reduction in the production of $A \beta$ peptide (Fig. 10). ${ }^{128,129}$ Lanabecestat (Eli Lilly, phase 3 clinical trials) displayed significant dose- and timedependent decreases in $A \beta 40, A \beta 42$, and $\mathrm{sA} \beta \mathrm{PP} \beta$ in plasma, CSF and the brain. ${ }^{130} \mathrm{~A}$ sulfonyl-based drug, namely, verubecestat (MK-8931, Merck, phase 3 clinical trials) is a potent and selective $\beta$-secretase inhibitor that has been shown to reduce the concentrations of $A \beta 40, A \beta 42$, and $\mathrm{SAPP} \beta$ in biological fluids (Fig. 10). ${ }^{131}$ However, in phase 3 trials verubecestat failed to decrease the $A \beta$ levels in a patient's brain. It should be noted that $\beta$-secretase plays a vital role in improving synaptic plasticity and cognitive performance. ${ }^{132}$ Therefore, inhibitors of $\beta$-secretase activity have given rise to severe adverse effects, which included reduced myelination of neurons, disturbances in glucose homeostasis and hepatotoxicity. This emphasises the need to adopt an unconventional design strategy such as the development of molecular clamps that bind to APP at the $\beta$ secretase cleavage site, prevent protease activity and consequently reduce the production of $A \beta$ peptide. ${ }^{133}$

4.2.2 $\gamma$-Secretase inhibitors. Semagacestat (Eli Lilly), which is a $\gamma$-secretase inhibitor, has enabled reductions in $A \beta$ concentrations in plasma and CSF in a dose-dependent manner. However, semagacestat failed in phase 3 clinical trials owing to severe side effects (Fig. 10). Further investigations revealed that apart from inhibiting $\gamma$-secretase, semagacestat interferes with the activity of Notch signalling proteins, which accounts for the observed side effects. ${ }^{134}$ On the other hand, an arylsulfonamide-based drug, namely, avagacestat, selectively inhibits the activity of $\gamma$-secretase without affecting the function of Notch protein, although it failed in phase 2 clinical trials. ${ }^{135}$ The naturally occurring cyclic sugar alcohol NIC5-15 (phase 3 trials) is a $\gamma$-secretase inhibitor that does not interfere with Notch functions, while pharmacokinetics and pharmacodynamics data have shown that NIC5-15 is safe and tolerable for humans without causing side effects (Fig. 10). ${ }^{136}$ Apart from processing APP, $\gamma$-secretase is involved in 


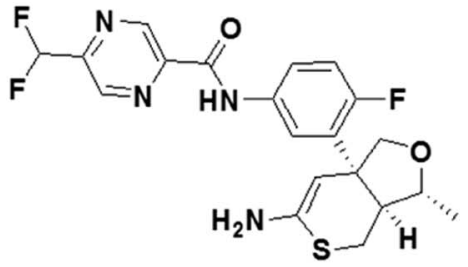

Elenbecestat

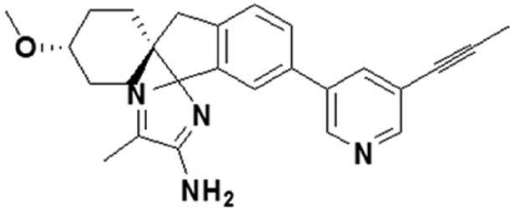

Lanabecestat<smiles>O=c1sn(-c2cccc3ccccc23)c(=O)n1Cc1ccccc1</smiles>

Tideglusib<smiles>COC1[C@@H](O)[C@@H](O)C(O)[C@H](O)[C@H]1O</smiles>

NIC5-15<smiles>COc1cnc(C(=O)Nc2ccc(F)c([C@]34CN(c5ncc(C)cn5)C[C@]3(C)CSC(N)=N4)c2)cn1</smiles>

LY3202626<smiles>CN1C(N)=NC(c2cc(NC(=O)c3ccc(F)cn3)ccc2F)CS1(=O)=O</smiles>

Verubecestat<smiles>CC(C)[C@H](O)C(=O)N[C@@H](C)C(=O)N[C@H]1C(=O)N(C)CCc2ccccc21</smiles>

Semagacestat

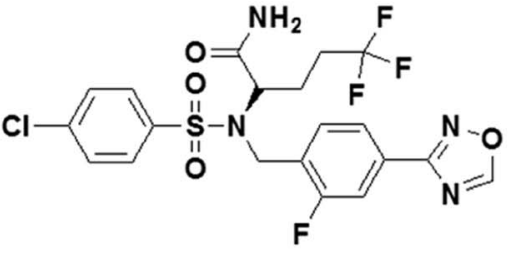

Avagacestat

Fig. 10 Molecular structures of inhibitors of $\beta$-secretase, $\gamma$-secretase and kinases that are undergoing clinical trials.

cleaving numerous physiologically important proteins such as Notch, E-cadherin, CD44, tyrosinase and TREM2. ${ }^{137}$ Therefore, targeting $\gamma$-secretase could potentially result in severe side effects by interfering with other physiological functions involving $\gamma$-secretase. As was mentioned in the $\beta$-secretase section, the development of molecular clamps that bind to the cleavage site in APP may prevent the activity of $\gamma$-secretase and possibly overcome this drawback to provide potential drug candidates.

4.2.3 Kinase inhibitors. Protein kinases have been identified as promising targets because of their involvement in the hyperphosphorylation of Tau. ${ }^{\mathbf{1 3 8}}$ An imbalance between the phosphorylation and dephosphorylation of Tau leads to an irreversibly hyperphosphorylated state of the protein. This process is driven by a reduction in the dephosphorylation of Tau or the overactivity of protein kinases. GSK3 $\beta$ plays a vital role in the Tau phosphorylation process and is responsible for the highest percentage of hyperphosphorylation that has been observed. An increase in the deposition of toxic $A \beta$ is known to significantly increase the activity of GSK3 $\beta$, although the actual mechanism is not clear. Therefore, GSK3 $\beta$ is a potential therapeutic target and has been pursued by many academic researchers and pharmaceutical companies. Many GSK3 $\beta$ inhibitors have been developed, including paullone, maleimide derivatives and indirubin. ${ }^{\mathbf{1 3 9}}$ However, high cytotoxicity and undesirable side effects have prevented these GSK3 $\beta$ inhibitors from entering clinical trials. Tideglusib is an orally available thiadiazolidinone-based GSK3 $\beta$ inhibitor, and in preclinical studies it has shown reductions in Tau phosphorylation and neuron loss in a mouse model (Fig. 10). ${ }^{\mathbf{1 4 0}}$ The other important Tau protein kinase is Cdk5. The dysfunctioning of Cdk5 contributes to senile plaques, neurofibrillary tangles, synaptic damage, mitochondrial dysfunction and cell cycle-dependent neuronal apoptosis. ${ }^{141}$ Small-molecule-based Cdk5 inhibitors have been reported in the literature; however, adverse side effects have limited their practical utility. The search for effective potent kinase inhibitors must follow a novel and unconventional molecular approach to drug design that includes finding ways to prevent the phosphorylation of Tau without altering other physiological functions of enzymes. One such 
unorthodox suggestion would comprise the design of molecular inhibitors that bind to an appropriate site on Tau protein and prevent interactions with kinases and the specific phosphorylation of Tau.

\subsection{Targeting inflammation}

Inflammation plays a key role in the pathology of $\mathrm{AD}$, and therefore targeting inflammatory pathways is considered to be a promising drug design strategy for $\mathrm{AD}^{38}$ To target inflammatory processes in $\mathrm{AD}$, two types of drug design strategies are being pursued: (i) the use of anti-inflammatory drugs for the downregulation of inflammation in the brain in $\mathrm{AD}$ and (ii) the activation of the immune system to counteract the pathological feature (A $\beta$ deposits) by initiating inflammation. Some of the promising drug candidates that have been developed to target inflammation in AD and are currently undergoing clinical trials are shown in Fig. 11. An imidazole-based drug, namely, azeliragon (Pfizer, phase 3 trials), is an inhibitor of the receptor for advanced glycation end products (RAGE), which is a key receptor in inflammatory processes. ${ }^{\mathbf{1 4 2}}$ The cell surface receptor RAGE binds to lipids and proteins, which are glycated when exposed to sugars (advanced glycation end products, AGEs). ${ }^{\mathbf{1 4 3}}$ Under conditions in $\mathrm{AD}$ the production of AGEs is upregulated, and these subsequently bind to RAGE causing inflammation and oxidative damage. Interestingly, azeliragon blocks AGE/ RAGE interactions and prevents inflammation. In clinical studies, treatment with a RAGE antagonist (azeliragon) gave rise to a decrease in the brain load of $\mathrm{A} \beta$ and also prevented cognitive decline.

Glutaminyl cyclase (QC), which is a metalloenzyme, has been shown to be upregulated in AD patients. QC catalyses the cyclisation of the glutamate residue at the N-terminus of $A \beta$ peptide to generate pyroglutamate- $A \beta$ (pGlu-A $\beta$ ), which is a highly pathogenic form of $A \beta .{ }^{144}$ pGlu-A $\beta$ is reported to be extremely toxic and is a major constituent of senile plaques in the brain in $\mathrm{AD} .{ }^{\mathbf{1 4 5}} \mathrm{A}$ benzimidazole-based drug, namely, PQ912 (phase 2 trials), has been shown to inhibit QC in rats, mice and humans. In vivo studies have indicated that PQ912 effectively reduces the pathology of amyloid by inhibiting QC and improves learning and memory. ${ }^{\mathbf{1 4 6}}$ A combination therapy using two drugs, namely, ibuprofen and cromolyn, has been developed (ALZT-OP1) for the treatment of AD (Fig. 11). Ibuprofen is a non-steroidal anti-inflammatory drug (suppresses cytokine release) that has been shown to have a significant effect on AD. On the other hand, cromolyn inhibits the aggregation of $A \beta$ monomer to form oligomers and fibrils under in vitro and in vivo conditions. ${ }^{147}$ ALZT-OP1 is currently undergoing phase 3 clinical trials, and the results are promising. A tetracycline derivative, namely, minocycline (phase 2 trials), is known for its anti-inflammatory properties; it effectively crosses the BBB and exhibits neuroprotective properties via the modulation of inflammation and oxidative stress. ${ }^{\mathbf{1 4 8}}$ Mice with $\mathrm{AD}$ treated with minocycline exhibited improved spatial memory accompanied by downregulation of the levels of anti-inflammatory cytokines<smiles>CC(C)Cc1ccc(C(C)C(=O)O)cc1</smiles>

ALZT-OP1

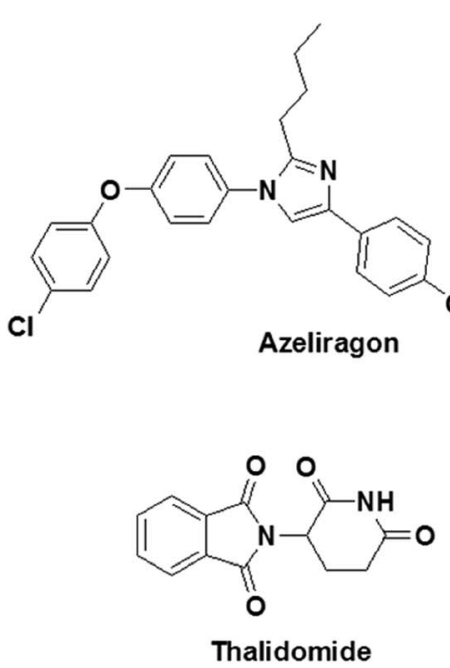

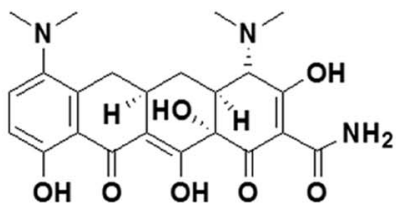

Minocycline<smiles>Cc1cccc(Cl)c1-c1c(=O)ncn2nc(Sc3ccc(F)cc3F)ccc12</smiles><smiles>CCCOc1ccc(N2C(=O)NC[C@H]2c2ccc3[nH]cnc3c2)cc1</smiles>

Fig. 11 Molecular structures of modulators of inflammation that are undergoing clinical trials. 
a)

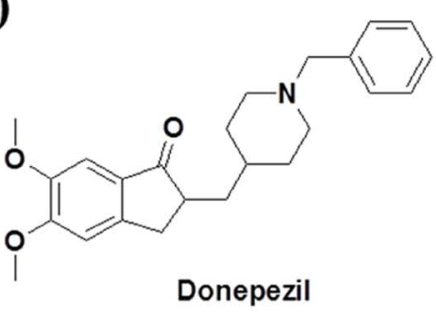

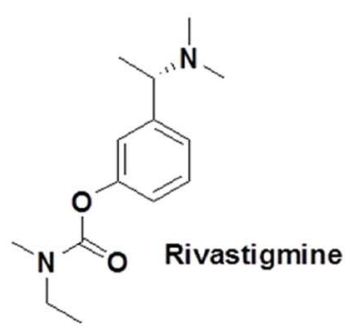

b)

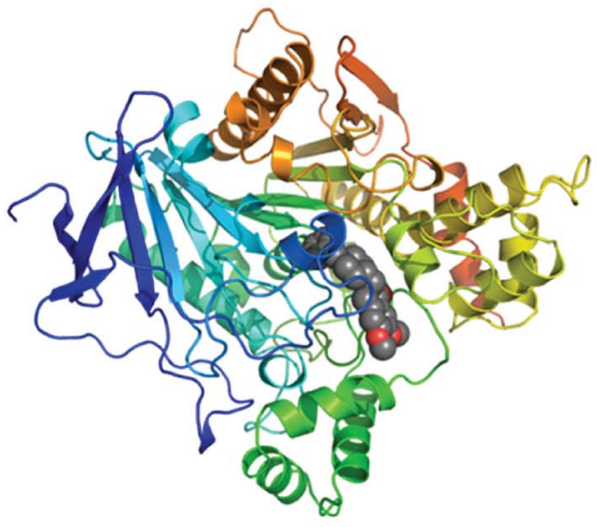<smiles>COc1ccc2c3c1O[C@H]1C[C@@H](OC(=O)c4ccccc4)C=C[C@@]31CCN(C)C2</smiles><smiles>CC12CC3CC(C)(C1)CC(N)(C3)C2</smiles>

Memantine

c)

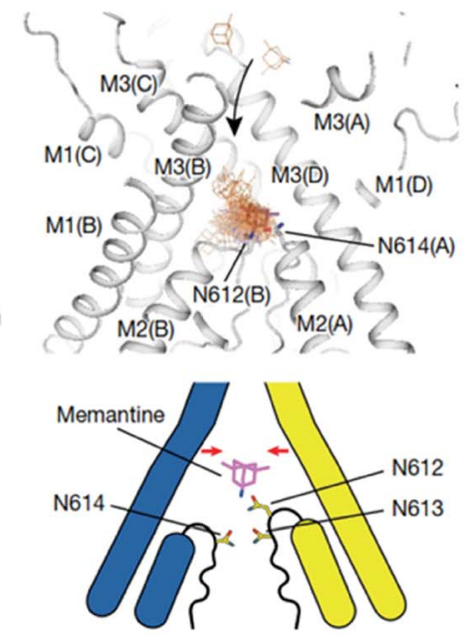

Fig. 12 (a) Cholinergic inhibitors and NMDA antagonist for treating AD. Molecular docking of donepezil (b) and memantine (c) with AChE and NMDA receptors, respectively. This figure has been adapted from ref. 156 with permission from Nature Publishing Group.

in the brain. Neflamapimod (phase 2 trials) is an inhibitor of the alpha isoform of p38 mitogen-activated protein kinases (p38 MAPK), which are known to activate pro-inflammatory cytokines. In microglia, p38 MAPK activate the release of tumor necrosis factor-alpha (TNF- $\alpha$ ) and IL-1 $\beta$ (pro-inflammatory cytokines) in response to various types of stressors such as A 342 . In neurons, p38 MAPK are involved in manipulating the localisation of Tau and neuronal plasticity. ${ }^{\mathbf{1 4 9}}$ A rat model of AD (Tg2576) treated with neflamapimod has shown a decrease of $50 \%$ in $A \beta$ load and a reduction in the level of pro-inflammatory cytokines such as IL-1 $\beta .{ }^{150}$ Thalidomide (phase 2 trials) is an immunomodulatory agent that exhibits anti-inflammatory activity by preventing the production of TNF- $\alpha .{ }^{151}$

Etanercept (Pfizer, phase 2 trials) is a fusion protein developed from a TNF- $\alpha$ receptor and the Fc end of the antibody immunoglobulin G. Etanercept binds to the pro-inflammatory cytokine TNF- $\alpha$ and prevents its function. ${ }^{152}$ In fact, etanercept is an FDA-approved treatment for various rheumatological and inflammatory skin diseases. However, etanercept failed to provide significant improvements in cognition and behavioural assays. ${ }^{153}$ Although none of the drug candidates that have been discussed are effective without causing significant side effects, there is a need to develop modulators of inflammation that target inflammation in the pathology of AD.

\subsection{Targeting cholinergic system}

Small molecules that target the cholinergic system and NMDA receptor are the only FDA-approved drugs available for the treatment of mild to moderate $\mathrm{AD}$ (Fig. 12). These drugs provide symptomatic and temporary relief to the patient by modulating the levels of neurotransmitters and do not directly treat the underlying disease mechanisms. ${ }^{32}$ Donepezil, galantamine, rivastigmine and tacrine are FDA-approved drugs that inhibit AChE and/or butyrylcholinesterase, which are involved in the degradation of the neurotransmitter ACh (Fig. 12). The inhibition of AChE activity leads to increased levels of ACh in synapses, which improves cholinergic transmission and provides temporary improvements in memory and cognition. A prodrug of galantamine (GLN-1062, phase 1 trials) has been developed to increase the lipophilicity to improve its BBB 
permeability. The prodrug GLN-1062 enters the brain and is enzymatically cleaved to release the active drug galantamine. ${ }^{\mathbf{1 5 4}}$ Histamine $\mathrm{H} 3$ receptors are predominantly expressed in the central nervous system over the peripheral nervous system and modulate cholinergic systems. An active histamine $\mathrm{H} 3$ receptor antagonist, namely, SUVN-G3031, was developed to treat the cognitive deficits found in $\mathrm{AD}$. In vivo studies have shown enhanced cholinergic signalling, reduced phosphorylation of Tau, and improved behavioural deficits. ${ }^{155}$ Memantine is a lowto medium-affinity NMDA antagonist of glutamate receptors in the brain. The binding of memantine affects NMDA receptoroperated ion channels, which reduces the effects of excitotoxic glutamate release. Memantine binds to the NMDA receptor with greater affinity than $\mathrm{Mg}^{2+}$, which inhibits the prolonged influx of $\mathrm{Ca}^{2+}$ from extrasynaptic receptors and forms the basis of neuronal excitotoxicity. ${ }^{156}$

\section{Conclusion and outlook}

We have described various molecular and pathophysiological mechanisms that encompass synaptic function, metal homeostasis, neural transmission, ATP production, memory formation and autophagy, among others that are severely affected in AD. Although multiple hypotheses have been proposed to explain the pathology of $\mathrm{AD}$, the amyloid hypothesis is the most widely accepted and is considered to be a realistic target for the development of diagnostic and therapeutic interventions. The current diagnosis mostly comprises evaluation of mental status, mood testing and cognitive behavior, but symptomatic and behavioral changes are manifested only in the advanced stages of $\mathrm{AD}$. The detection of biomarkers ( $\mathrm{A} \beta$ load) in biological fluids such as blood and CSF via in vivo fluorescence imaging of the human brain using selective NIR probes is a promising approach, which needs to be further developed into a viable technique and validated for clinical use. In vivo fluorescence imaging of the human brain is currently limited by the technique (unavailability of suitable equipment) itself, but the situation is expected to change in the near future. At present, PET is the most promising technique for the early diagnosis of AD. Although some probes have been approved for clinical use, the lack of highly selective and sensitive PET probes for biomarkers of $\mathrm{AD}$ ( $\mathrm{A} \beta$ and Tau aggregates) has limited their widespread clinical utility. Nevertheless, PET imaging coupled with MRI is expected to enhance our understanding of structural and functional changes in the brain during the progression of $\mathrm{AD}$, which can be used to develop brain maps as a standard in brain analysis for the early diagnosis of AD. The detection of biomarkers in the brain is still a challenging task and requires sophisticated, safe and practically viable techniques. Recent efforts in the identification of biomarkers (APP/ $A \beta 42$ and $A \beta 40 / A \beta 42$ ) in biological fluids (blood) have been promising. In this study, a composite parameter was derived from the concentrations of biomarkers to define the amyloid load in the brain with an accuracy of $90 \%$ and statistical significance. However, further standardisation and improvements in sensitivity and accuracy are necessary for its practical utilisation. Furthermore, many biomarkers have a direct or indirect role in the pathology of $\mathrm{AD}$, and multiplexing their analysis in biological fluids could possibly lead to a realistic and timely diagnosis of $\mathrm{AD}$.

Progress in the development of therapeutic interventions for preventing the symptoms of $\mathrm{AD}$ has been encouraging, although several drug candidates have unfortunately failed at various stages of clinical trials. These failures are mainly attributed to the fact that most of these drugs interfere with one of the many disease pathways of multifactorial AD. In other words, the complex pathophysiology of $\mathrm{AD}$ involves the dysfunction of various key molecular pathways, and successful drug design must take into account the integration of multiple disease pathways. In this context, the multifunctional approach that we adopted in our laboratory could be an effective and promising strategy for developing drugs to target the multifaceted pathology of $\mathrm{AD}$. In fact, targeting amyloid aggregation (A $\beta$ and Tau aggregates) using small molecules, natural products, peptidomimetics and metal chelators has been actively pursued; however, the discouraging outcomes have reoriented the attention of researchers to focus on the development of multifunctional drug candidates. Such drug candidates must be capable of preventing the aggregation of $A \beta$ and Tau, metal chelation, metal-induced aggregation, the generation of excess ROS and oxidative stress, damage to biomolecules by ROS, inflammation, mitochondrial damage, synaptic toxicity, the activity of secretase and kinase enzymes and many other processes. In recent years, immunotherapy has been considered to be one of the most probable therapeutic strategies for targeting the clearance of amyloid from the brain and has been actively pursued by leading pharmaceutical companies. Although immunotherapy is promising, a few critical issues, such as low BBB permeability, size, autoimmune response, stability, retention in the brain and the high cost of development and treatment, need to be addressed before it finds practical application. Preventing the activity of enzymes such as $\beta$-secretase, $\gamma$-secretase and kinases in the pathology of $\mathrm{AD}$ is a viable strategy for drug discovery. Current approaches to targeting these enzymes have shown adverse side effects, which were attributed to their vital role in many other biological process in the brain. Thus, we propose the design of molecular clamps that bind to the $\beta$-secretase $/ \gamma$-secretase cleavage site in APP or specific phosphorylation sites in Tau and subsequently prevent the undesirable specific activity of enzymes. Such a therapeutic design approach may yield potential drug candidates that effectively inhibit enzymatic (protease/ phosphorylation) activity without interfering with the other biological functions of enzymes. Drugs that target inflammation and the cholinergic system have mostly provided symptomatic relief, although these drugs can be made potent with improved therapeutic effects if used in combination with multifunctional drugs that target the core pathology of AD. Our understanding of $\mathrm{AD}$ in terms of complex molecular and pathophysiological mechanisms is very limited in spite of the vast available literature. In fact, the actual cause and realistic molecular targets need to be discovered and validated on the basis of existing and new knowledge. AD has become a common epidemic worldwide, and the research community across 
various disciplines needs to collaborate to provide better and faster solutions in terms of managing the disease via effective diagnostic and therapeutic interventions. The ambitious neuroscience and brain projects launched in the United States (Brain Research through Advancing Innovative Neurotechnologies (BRAIN) Initiative), Europe (Human Brain Project (HBP)), Japan (Brain Mapping by Integrated Neurotechnologies for Disease Studies (Brain/MINDS)) and China (China Brain Project) with the aim of developing novel technologies and unraveling mysteries of the brain are expected to help researchers to understand and develop effective diagnostic and therapeutic strategies for brain disorders, mainly AD. Although many individual research groups are actively involved, there are no dedicated grand initiatives in the area of neuroscience and brain disorders in India. Notwithstanding the setbacks, we are hopeful that research efforts and knowledge accumulated over the years will supplement the ongoing and forthcoming efforts in drug discovery to successfully develop effective diagnostic and therapeutic interventions for $\mathrm{AD}$ in the near future.

\section{Conflicts of interest}

There are no conflicts to declare.

\section{Acknowledgements}

We thank Prof. C. N. R. Rao FRS for constant support and encouragement, JNCASR, the Swarnajayanti Fellowship, the Department of Science and Technology (DST), Government of India (Grant: DST/SJF/CSA-02/2015-2016), TRC-JNCASR (TRCJNC/ TG/4426) and Sheikh Saqr Laboratory (SSL), ICMS-JNCASR, for financial support.

\section{Reference}

1 M. Prince, R. Bryce, E. Albanese, A. Wimo, W. Ribeiro and C. P. Ferri, Alzheimer's Dementia, 2013, 9, 63-75.

2 K. Rajasekhar, M. Chakrabarti and T. Govindaraju, Chem. Commun., 2015, 51, 13434-13450.

3 R. E. Becker, N. H. Greig, E. Giacobini, L. S. Schneider and L. Ferrucci, Nat. Rev. Drug Discovery, 2013, 13, 156.

4 Y. Huang and L. Mucke, Cell, 2012, 148, 1204-1222.

5 Alzheimer's Association, Alzheimer's Dementia, 2016, 12, 459-509.

6 http://www.sciwri.club/archives/6194.

7 I. W. Hamley, Chem. Rev., 2012, 112, 5147-5192.

8 A. S. DeToma, S. Salamekh, A. Ramamoorthy and M. H. Lim, Chem. Soc. Rev., 2012, 41, 608-621.

9 C. A. Ross and M. A. Poirier, Nat. Med., 2004, 10, S10.

10 S.-Y. Hung and W.-M. Fu, J. Biomed. Sci., 2017, 24, 47.

11 D. J. Selkoe and J. Hardy, EMBO Mol. Med., 2016, 8, 595-608.

12 S. I. A. Cohen, S. Linse, L. M. Luheshi, E. Hellstrand, D. A. White, L. Rajah, D. E. Otzen, M. Vendruscolo, C. M. Dobson and T. P. J. Knowles, Proc. Natl. Acad. Sci. U. S. A., 2013, 110, 9758-9763.

13 M. P. Murphy and H. LeVine, J. Alzheimer's Dis., 2010, 19, 311.
14 L. Buée, T. Bussière, V. Buée-Scherrer, A. Delacourte and P. R. Hof, Brain Res. Rev., 2000, 33, 95-130.

15 K. Iqbal, F. Liu, C.-X. Gong and I. Grundke-Iqbal, Curr. Alzheimer Res., 2010, 7, 656-664.

16 R. B. Maccioni, G. Farías, I. Morales and L. Navarrete, Arch. Med. Res., 2010, 41, 226-231.

17 C. J. Lansdall, Biosci. Horiz., 2014, 7, hzu002.

18 G. S. Bloom, JAMA Neurol., 2014, 71, 505-508.

19 F. Panza, V. Solfrizzi, D. Seripa, B. P. Imbimbo, M. Lozupone, A. Santamato, C. Zecca, M. R. Barulli, A. Bellomo, A. Pilotto, A. Daniele, A. Greco and G. Logroscino, BioMed Res. Int., 2016, 2016, 3245935.

20 K. J. Barnham and A. I. Bush, Chem. Soc. Rev., 2014, 43, 6727-6749.

21 D. Maity and T. Govindaraju, Chem. Commun., 2010, 46, 4499-4501.

22 D. Maity, A. K. Manna, D. Karthigeyan, T. K. Kundu, S. K. Pati and T. Govindaraju, Chem.-Eur. J., 2011, 17, 11152-11161.

23 D. Maity and T. Govindaraju, Chem. Commun., 2012, 48, 1039-1041.

24 M. G. Savelieff, S. Lee, Y. Liu and M. H. Lim, ACS Chem. Biol., 2013, 8, 856-865.

25 P. Faller, C. Hureau and G. La Penna, Acc. Chem. Res., 2014, 47, 2252-2259.

26 S. J. C. Lee, E. Nam, H. J. Lee, M. G. Savelieff and M. H. Lim, Chem. Soc. Rev., 2017, 46, 310-323.

27 A. I. Bush and R. E. Tanzi, Neurotherapeutics, 2008, 5, 421432.

28 H. Sies, Redox Biol., 2015, 4, 180-183.

29 N. Narayanaswamy, S. Narra, R. R. Nair, D. K. Saini, P. Kondaiah and T. Govindaraju, Chem. Sci., 2016, 7, 2832-2841.

30 A. Eckert, K. Schmitt and J. Götz, Alzheimer's Res. Ther., 2011, 3, 15.

31 Y. Feng and X. Wang, Oxid. Med. Cell. Longevity, 2012, 2012, 17.

32 P. Francis, A. Palmer, M. Snape and G. Wilcock, J. Neurol., Neurosurg. Psychiatry, 1999, 66, 137-147.

33 A. V. Terry and J. J. Buccafusco, J. Pharmacol. Exp. Ther., 2003, 306, 821-827.

34 R. Wang and P. H. Reddy, J. Alzheimer's Dis., 2017, 57, 10411048.

35 R. Malinow, Curr. Opin. Neurobiol., 2012, 22, 559-563.

36 G. Neuroinflammation Working, H. Akiyama, S. Barger, S. Barnum, B. Bradt, J. Bauer, G. M. Cole, N. R. Cooper, P. Eikelenboom, M. Emmerling, B. L. Fiebich, C. E. Finch, S. Frautschy, W. S. T. Griffin, H. Hampel, M. Hull, G. Landreth, L. F. Lue, R. Mrak, I. R. Mackenzie, P. L. McGeer, M. K. O'Banion, J. Pachter, G. Pasinetti, C. Plata-Salaman, J. Rogers, R. Rydel, Y. Shen, W. Streit, R. Strohmeyer, I. Tooyoma, F. L. Van Muiswinkel, R. Veerhuis, D. Walker, S. Webster, B. Wegrzyniak, G. Wenk and T. Wyss-Coray, Neurobiol. Aging, 2000, 21, 383-421.

37 V. H. Perry and C. Holmes, Nat. Rev. Neurol., 2014, 10, 217. 
38 T. Wyss-Coray and J. Rogers, Cold Spring Harbor Perspect. Med., 2012, 2, a006346.

39 E. Zotova, J. A. R. Nicoll, R. Kalaria, C. Holmes and D. Boche, Alzheimer's Res. Ther., 2010, $2,1$.

40 D. Glick, S. Barth and K. F. Macleod, J. Pathol., 2010, 221, 312.

41 A. Zare-shahabadi, E. Masliah, G. V. W. Johnson and N. Rezaei, Rev. Neurosci., 2015, 26, 385-395.

42 J. W. Steele, E. Fan, Y. Kelahmetoglu, Y. Tian and V. Bustos, Postdoc J., 2013, 1, 21-34.

43 A. D. Smith, Proc. Natl. Acad. Sci. U. S. A., 2002, 99, 41354137.

44 E. Bagyinszky, Y. C. Youn, S. S. A. An and S. Kim, J. Toxicol. Environ. Health Sci., 2014, 6, 133-147.

45 M. Staderini, M. A. Martin, M. L. Bolognesi and J. C. Menendez, Chem. Soc. Rev., 2015, 44, 1807-1819.

46 M.-m. Xu, W.-m. Ren, X.-c. Tang, Y.-h. Hu and H.-y. Zhang, Acta Pharmacol. Sin., 2016, 37, 719.

47 P. Verwilst, H. S. Kim, S. Kim, C. Kang and J. S. Kim, Chem. Soc. Rev., 2018, 47, 2249-2265.

48 J. Hatai, L. Motiei and D. Margulies, J. Am. Chem. Soc., 2017, 139, 2136-2139.

49 K. Rajasekhar, N. Narayanaswamy, N. A. Murugan, G. Kuang, H. Ågren and T. Govindaraju, Sci. Rep., 2016, 6, 23668.

50 K. Rajasekhar, N. Narayanaswamy, N. A. Murugan, K. Viccaro, H.-G. Lee, K. Shah and T. Govindaraju, Biosens. Bioelectron., 2017, 98, 54-61.

51 A. G. Vlassenko, T. L. S. Benzinger and J. C. Morris, Biochim. Biophys. Acta, 2012, 1822, 370-379.

52 W. E. Klunk, H. Engler, A. Nordberg, Y. Wang, G. Blomqvist, D. P. Holt, M. Bergström, I. Savitcheva, G. F. Huang, S. Estrada, B. Ausén, M. L. Debnath, J. Barletta, J. C. Price, J. Sandell, B. J. Lopresti, A. Wall, P. Koivisto, G. Antoni, C. A. Mathis and B. Långström, Ann. Neurol., 2004, 55, 306-319.

53 D. F. Wong, P. B. Rosenberg, Y. Zhou, A. Kumar, V. Raymont, H. T. Ravert, R. F. Dannals, A. Nandi, J. R. Brašić, W. Ye, J. Hilton, C. Lyketsos, H. F. Kung, A. D. Joshi, D. M. Skovronsky and M. J. Pontecorvo, J. Nucl. Med., 2010, 51, 913-920.

54 O. Sabri, M. N. Sabbagh, J. Seibyl, H. Barthel, H. Akatsu, Y. Ouchi, K. Senda, S. Murayama, K. Ishii, M. Takao, T. G. Beach, C. C. Rowe, J. B. Leverenz, B. Ghetti, J. W. Ironside, A. M. Catafau, A. W. Stephens, A. Mueller, N. Koglin, A. Hoffmann, K. Roth, C. Reininger and W. J. Schulz-Schaeffer, Alzheimer's Dementia, 2015, 11, 964-974.

55 H. Watanabe, M. Ono and H. Saji, Sci. World J., 2015, 2015, 6.

56 N. Okamura, S. Furumoto, M. T. Fodero-Tavoletti, R. S. Mulligan, R. Harada, P. Yates, S. Pejoska, Y. Kudo, C. L. Masters, K. Yanai, C. C. Rowe and V. L. Villemagne, Brain, 2014, 137, 1762-1771.

57 M. Brendel, A. Jaworska, F. Probst, F. Overhoff, V. Korzhova, S. Lindner, J. Carlsen, P. Bartenstein, R. Harada, Y. Kudo,
C. Haass, F. Van Leuven, N. Okamura, J. Herms and A. Rominger, J. Nucl. Med., 2016, 57, 792-798.

58 L. Declercq, S. Celen, J. Lecina, M. Ahamed, T. Tousseyn, D. Moechars, J. Alcazar, M. Ariza, K. Fierens, A. Bottelbergs, J. Mariën, R. Vandenberghe, I. J. Andres, K. Van Laere, A. Verbruggen and G. Bormans, Mol. Imaging, 2016, 15, 1-15.

59 M. Ono and H. Saji, Int. J. Mol. Imaging, 2011, 2011, 543267. 60 A. B. Newberg, N. A. Wintering, K. Plössl, J. Hochold, M. G. Stabin, M. Watson, D. Skovronsky, C. M. Clark, M.-P. Kung and H. F. Kung, J. Nucl. Med., 2006, 47, 748-754. 61 K. A. Johnson, N. C. Fox, R. A. Sperling and W. E. Klunk, Cold Spring Harbor Perspect. Med., 2012, 2, a006213.

62 R. Wolz, V. Julkunen, J. Koikkalainen, E. Niskanen, D. P. Zhang, D. Rueckert, H. Soininen and J. Lötjönen, The Alzheimer's Disease Neuroimaging, PLoS One, 2011, 6, e25446.

63 B. Olsson, R. Lautner, U. Andreasson, A. Öhrfelt, E. Portelius, M. Bjerke, M. Hölttä, C. Rosén, C. Olsson, G. Strobel, E. Wu, K. Dakin, M. Petzold, K. Blennow and H. Zetterberg, Lancet Neurol., 2016, 15, 673-684.

64 K. Blennow, Neurology and Therapy, 2017, 6, 15-24.

65 L. Sakka, G. Coll and J. Chazal, Eur. Ann. Otorhinolaryngol. Head Neck Dis., 2011, 128, 309-316.

66 L.-F. Lue, A. Guerra and D. G. Walker, Neurology and Therapy, 2017, 6, 25-36.

67 Y. Liu, H. Qing and Y. Deng, Int. J. Mol. Sci., 2014, 15, 78657882.

68 A. Koyama, O. I. Okereke, T. Yang, D. Blacker, D. J. Selkoe and F. Grodstein, Arch. Neurol., 2012, 69, 824-831.

69 A. Nakamura, N. Kaneko, V. L. Villemagne, T. Kato, J. Doecke, V. Doré, C. Fowler, Q.-X. Li, R. Martins, C. Rowe, T. Tomita, K. Matsuzaki, K. Ishii, K. Ishii, Y. Arahata, S. Iwamoto, K. Ito, K. Tanaka, C. L. Masters and K. Yanagisawa, Nature, 2018, 554, 249.

70 J. Cummings, G. Lee, T. Mortsdorf, A. Ritter and K. Zhong, Alzheimer's Dementia, 2017, 3, 367-384.

71 Z. Liu, A. Zhang, H. Sun, Y. Han, L. Kong and X. Wang, RSC Adv., 2017, 7, 6046-6058.

72 S.-Y. Hung and W.-M. Fu, J. Biomed. Sci., 2017, 24, 47.

73 K. Cisek, G. L. Cooper, C. J. Huseby and J. Kuret, Curr. Alzheimer Res., 2014, 11, 918-927.

74 S. Salloway, R. Sperling, R. Keren, A. P. Porsteinsson, C. H. van Dyck, P. N. Tariot, S. Gilman, D. Arnold, S. Abushakra, C. Hernandez, G. Crans, E. Liang, G. Quinn, M. Bairu, A. Pastrak and J. M. Cedarbaum, Neurology, 2011, 77, 1253-1262.

75 F. van Bebber, D. Paquet, A. Hruscha, B. Schmid and C. Haass, Neurobiol. Dis., 2010, 39, 265-271.

76 J. Bieschke, Neurotherapeutics, 2013, 10, 429-439.

77 W.-J. Du, J.-J. Guo, M.-T. Gao, S.-Q. Hu, X.-Y. Dong, Y.-F. Han, F.-F. Liu, S. Jiang and Y. Sun, Sci. Rep., 2015, 5, 7992.

78 T. Kai, L. Zhang, X. Wang, A. Jing, B. Zhao, X. Yu, J. Zheng and F. Zhou, ACS Chem. Neurosci., 2015, 6, 879-888.

79 J. Bieschke, M. Herbst, T. Wiglenda, R. P. Friedrich, A. Boeddrich, F. Schiele, D. Kleckers, J. M. Lopez del Amo, 
B. A. Grüning, Q. Wang, M. R. Schmidt, R. Lurz, R. Anwyl, S. Schnoegl, M. Fändrich, R. F. Frank, B. Reif, S. Günther, D. M. Walsh and E. E. Wanker, Nat. Chem. Biol., 2011, 8, 93. 80 A. Daccache, C. Lion, N. Sibille, M. Gerard, C. Slomianny, G. Lippens and P. Cotelle, Neurochem. Int., 2011, 58, 700707.

81 I. Avan, C. D. Hall and A. R. Katritzky, Chem. Soc. Rev., 2014, 43, 3575-3594.

82 A. F. Mark, Curr. Opin. Drug Discovery Dev., 2002, 2, 417-423. 83 P. M. Seidler, D. R. Boyer, J. A. Rodriguez, M. R. Sawaya, D. Cascio, K. Murray, T. Gonen and D. S. Eisenberg, Nat. Chem., 2017, 10, 170.

84 L. O. Tjernberg, J. Näslund, F. Lindqvist, J. Johansson, A. R. Karlström, J. Thyberg, L. Terenius and C. Nordstedt, J. Biol. Chem., 1996, 271, 8545-8548.

85 J. Vagner, H. Qu and V. J. Hruby, Curr. Opin. Chem. Biol., 2008, 12, 292-296.

86 J. Kaffy, D. Brinet, J.-L. Soulier, I. Correia, N. Tonali, K. F. Fera, Y. Iacone, A. R. F. Hoffmann, L. Khemtémourian, B. Crousse, M. Taylor, D. Allsop, M. Taverna, O. Lequin and S. Ongeri, J. Med. Chem., 2016, 59, 2025-2040.

87 S. Pellegrino, N. Tonali, E. Erba, J. Kaffy, M. Taverna, A. Contini, M. Taylor, D. Allsop, M. L. Gelmi and S. Ongeri, Chem. Sci., 2017, 8, 1295-1302.

88 K. Rajasekhar, N. Narayanaswamy, P. Mishra, S. N. Suresh, R. Manjithaya and T. Govindaraju, ChemPlusChem, 2014, 79, 25-30.

89 K. Rajasekhar, S. N. Suresh, R. Manjithaya and T. Govindaraju, Sci. Rep., 2015, 5, 8139.

90 L. G. Friedman, Y. H. Qureshi and W. H. Yu, Neurotherapeutics, 2015, 12, 94-108.

91 S. Gilead and E. Gazit, Angew. Chem., Int. Ed., 2004, 43, 4041-4044.

92 J. P. Turner, T. Lutz-Rechtin, K. A. Moore, L. Rogers, O. Bhave, M. A. Moss and S. L. Servoss, ACS Chem. Neurosci., 2014, 5, 552-558.

93 A. Paul, K. C. Nadimpally, T. Mondal, K. Thalluri and B. Mandal, Chem. Commun., 2015, 51, 2245-2248.

94 H. Amijee, C. Bate, A. Williams, J. Virdee, R. Jeggo, D. Spanswick, D. I. C. Scopes, J. M. Treherne, S. Mazzitelli, R. Chawner, C. E. Eyers and A. J. Doig, Biochemistry, 2012, 51, 8338-8352.

95 M. G. Savelieff, A. S. DeToma, J. S. Derrick and M. H. Lim, Acc. Chem. Res., 2014, 47, 2475-2482.

96 M. Jensen, A. Canning, S. Chiha, P. Bouquerel, J. T. Pedersen, J. Ostergaard, O. Cuvillier, I. Sasaki, C. Hureau and P. Faller, Chem.-Eur. J., 2012, 18, 4836-4839.

97 A. B. Caballero, L. Terol-Ordaz, A. Espargaró, G. Vázquez, E. Nicolás, R. Sabaté and P. Gamez, Chem.-Eur. J., 2016, 22, 7268-7280.

98 K. Rajasekhar, C. Madhu and T. Govindaraju, ACS Chem. Neurosci., 2016, 7, 1300-1310.

99 A. Robert, Y. Liu, M. Nguyen and B. Meunier, Acc. Chem. Res., 2015, 48, 1332-1339.

100 R. A. Cherny, C. S. Atwood, M. E. Xilinas, D. N. Gray, W. D. Jones, C. A. McLean, K. J. Barnham, I. Volitakis,
F. W. Fraser, Y.-S. Kim, X. Huang, L. E. Goldstein, R. D. Moir, J. T. Lim, K. Beyreuther, H. Zheng, R. E. Tanzi, C. L. Masters and A. I. Bush, Neuron, 2001, 30, 665-676.

101 P. J. Crouch, M. S. Savva, L. W. Hung, P. S. Donnelly, A. I. Mot, S. J. Parker, M. A. Greenough, I. Volitakis, P. A. Adlard, R. A. Cherny, C. L. Masters, A. I. Bush, K. J. Barnham and A. R. White, J. Neurochem., 2011, 119, 220-230.

102 A. K. Sharma, S. T. Pavlova, J. Kim, D. Finkelstein, N. J. Hawco, N. P. Rath, J. Kim and L. M. Mirica, J. Am. Chem. Soc., 2012, 134, 6625-6636.

103 C. Lu, Y. Guo, J. Yan, Z. Luo, H.-B. Luo, M. Yan, L. Huang and X. Li, J. Med. Chem., 2013, 56, 5843-5859.

104 J. Geng, M. Li, L. Wu, J. Ren and X. Qu, J. Med. Chem., 2012, 55, 9146-9155.

105 K. Rajasekhar, K. Mehta and T. Govindaraju, ACS Chem. Neurosci., 2018, 9, 1432-1440.

106 L. Pagani and A. Eckert, Int. J. Alzheimer's Dis., 2011, 2011, 925050.

107 C. Guo, L. Sun, X. Chen and D. Zhang, Neural Regener. Res., 2013, 8, 2003-2014.

108 M.-Y. Cha, S.-H. Han, S. M. Son, H.-S. Hong, Y.-J. Choi, J. Byun and I. Mook-Jung, PLoS One, 2012, 7, e34929.

109 P. A. Ott, Nat. Rev. Clin. Oncol., 2018, 15, 267-268.

110 A. Fettelschoss, F. Zabel and M. F. Bachmann, Hum. Vaccines Immunother., 2014, 10, 847-851.

111 A. Muhs, D. T. Hickman, M. Pihlgren, N. Chuard, V. Giriens, C. Meerschman, I. van der Auwera, F. van Leuven, M. Sugawara, M.-C. Weingertner, B. Bechinger, R. Greferath, N. Kolonko, L. Nagel-Steger, D. Riesner, R. O. Brady, A. Pfeifer and C. Nicolau, Proc. Natl. Acad. Sci. U. S. A., 2007, 104, 9810-9815.

112 C. Theunis, N. Crespo-Biel, V. Gafner, M. Pihlgren, M. P. López-Deber, P. Reis, D. T. Hickman, O. Adolfsson, N. Chuard, D. M. Ndao, P. Borghgraef, H. Devijver, F. Van Leuven, A. Pfeifer and A. Muhs, PLoS One, 2013, 8, e72301.

113 A.-M. Lacosta, M. Pascual-Lucas, P. Pesini, D. Casabona, V. Pérez-Grijalba, I. Marcos-Campos, L. Sarasa, J. Canudas, H. Badi, I. Monleón, I. San-José, J. Munuera, O. Rodríguez-Gómez, C. Abdelnour, A. Lafuente, M. Buendía, M. Boada, L. Tárraga, A. Ruiz and M. Sarasa, Alzheimer's Res. Ther., 2018, 10, 12.

114 E. Kontsekova, N. Zilka, B. Kovacech, P. Novak and M. Novak, Alzheimer's Res. Ther., 2014, 6, 44.

115 C. Wiessner, K.-H. Wiederhold, A. C. Tissot, P. Frey, S. Danner, L. H. Jacobson, G. T. Jennings, R. Lüönd, R. Ortmann, J. Reichwald, M. Zurini, A. Mir, M. F. Bachmann and M. Staufenbiel, J. Neurosci., 2011, 31, 9323-9331.

116 H. Davtyan, A. Ghochikyan, I. Petrushina, A. Hovakimyan, A. Davtyan, A. Poghosyan, A. M. Marleau, N. Movsesyan, A. Kiyatkin, S. Rasool, A. K. Larsen, P. J. Madsen, K. M. Wegener, D. K. Ditlevsen, D. H. Cribbs, L. O. Pedersen and M. G. Agadjanyan, J. Neurosci., 2013, 33, 4923-4934. 
117 D. Lambracht-Washington and R. N. Rosenberg, Transl. Neurosci., 2012, 3, 307-313.

118 J. Sevigny, P. Chiao, T. Bussière, P. H. Weinreb, L. Williams, M. Maier, R. Dunstan, S. Salloway, T. Chen, Y. Ling, J. O'Gorman, F. Qian, M. Arastu, M. Li, S. Chollate, M. S. Brennan, O. Quintero-Monzon, R. H. Scannevin, H. M. Arnold, T. Engber, K. Rhodes, J. Ferrero, Y. Hang, A. Mikulskis, J. Grimm, C. Hock, R. M. Nitsch and A. Sandrock, Nature, 2016, 537, 50.

119 T. Blaettler, J. Smith, J. Smith, R. Paul, V. Asnaghi, R. Fuji, A. Quartino, L. Honigberg, M. A. Rabbia Jr, S. Yule, S. Ostrowitzki and P. Fontoura, Alzheimer's Dementia, 2016, 12, P609.

120 M. Ultsch, B. Li, T. Maurer, M. Mathieu, O. Adolfsson, A. Muhs, A. Pfeifer, M. Pihlgren, T. W. Bainbridge, M. Reichelt, J. A. Ernst, C. Eigenbrot, G. Fuh, J. K. Atwal, R. J. Watts and W. Wang, Sci. Rep., 2016, 6, 39374.

121 S. Ostrowitzki, D. Deptula, L. Thurfjell, et al., Arch. Neurol., 2012, 69, 198-207.

122 R. Lai, V. Logovinsky, J. M. Kaplow, K. Gu, Y. Yu, C. Möller, B. Navia, C. Swanson, L. Lannfelt and A. Satlin, Alzheimer's Dementia, 2013, 9, P689.

123 H. Feinberg, J. W. Saldanha, L. Diep, A. Goel, A. Widom, G. M. Veldman, W. I. Weis, D. Schenk and G. S. Basi, Alzheimer's Res. Ther., 2014, 6, 31.

124 G. A. N. Crespi, S. J. Hermans, M. W. Parker and L. A. Miles, Sci. Rep., 2015, 5, 9649.

125 J. Bright, S. Hussain, V. Dang, S. Wright, B. Cooper, T. Byun, C. Ramos, A. Singh, G. Parry, N. Stagliano and I. GriswoldPrenner, Neurobiol. Aging, 2015, 36, 693-709.

126 K. Yanamandra, N. Kfoury, H. Jiang, T. E. Mahan, S. Ma, S. E. Maloney, D. F. Wozniak, M. I. Diamond and D. M. Holtzman, Neuron, 2013, 80, 402-414.

127 M. Ufer, M.-L. Rouzade-Dominguez, G. Huledal, N. Pezous, A. Avrameas, O. David, S. Kretz, K. Kucher, U. Neumann, J.-H. Cha, A. Graf and C. Lopez-Lopez, Alzheimer's Dementia, 2016, 12, P200.

128 R. Y. K. Lai, B. Darpo, S. Dayal, N. Hall, M.-K. Chang, B. Albala, J. Ferry and B. Rege, Alzheimer's Dementia, 2017, 13, P250-P251.

129 R. Yan, Transl. Neurodegener., 2016, 5, 13.

130 S. Eketjäll, J. Janson, K. Kaspersson, A. Bogstedt, F. Jeppsson, J. Fälting, S. B. Haeberlein, A. R. Kugler, R. C. Alexander and G. Cebers, J. Alzheimer's Dis., 2016, 50, 1109-1123.

131 M. E. Kennedy, A. W. Stamford, X. Chen, K. Cox, J. N. Cumming, M. F. Dockendorf, M. Egan, L. Ereshefsky, R. A. Hodgson, L. A. Hyde, S. Jhee, H. J. Kleijn, R. Kuvelkar, W. Li, B. A. Mattson, H. Mei, J. Palcza, J. D. Scott, M. Tanen, M. D. Troyer, J. L. Tseng, J. A. Stone, E. M. Parker and M. S. Forman, Sci. Transl. Med., 2016, 8, 363ra150.

132 C. Venugopal, C. M. Demos, K. S. J. Rao, M. A. Pappolla and K. Sambamurti, CNS Neurol. Disord.: Drug Targets, 2008, 7, 278-294.

133 L. Rajendran, A. Schneider, G. Schlechtingen, S. Weidlich, J. Ries, T. Braxmeier, P. Schwille, J. B. Schulz,
C. Schroeder, M. Simons, G. Jennings, H.-J. Knölker and K. Simons, Science, 2008, 320, 520-523.

134 R. S. Doody, R. Raman, M. Farlow, T. Iwatsubo, B. Vellas, S. Joffe, K. Kieburtz, F. He, X. Sun, R. G. Thomas, P. S. Aisen, E. Siemers, G. Sethuraman and R. Mohs, N. Engl. J. Med., 2013, 369, 341-350.

135 V. Coric, C. H. van Dyck, S. Salloway, et al., Arch. Neurol., 2009, 69, 1430-1440.

136 H. Grossman, G. Marzloff, X. Luo, D. LeRoith, M. Sano and G. Pasinetti, Alzheimer's Dementia, 5, P259.

137 X. Zhang, Y. Li, H. Xu and Y.-w. Zhang, Front. Cell. Neurosci., 2014, 8, 427.

138 V. Tell and A. Hilgeroth, Front. Cell. Neurosci., 2013, 7, 189. 139 P. J. Dolan and G. V. W. Johnson, Curr. Opin. Drug Discovery Dev., 2010, 13, 595-603.

140 J. M. Domínguez, A. Fuertes, L. Orozco, M. del MonteMillán, E. Delgado and M. Medina, J. Biol. Chem., 2012, 287, 893-904.

141 S.-L. Liu, C. Wang, T. Jiang, L. Tan, A. Xing and J.-T. Yu, Mol. Neurobiol., 2016, 53, 4328-4342.

142 M. N. Sabbagh, A. Agro, J. Bell, P. S. Aisen, E. Schweizer and D. Galasko, Alzheimer Dis. Assoc. Disord., 2011, 25, 206-212.

143 L.-F. Lue, D. G. Walker, S. Jacobson and M. Sabbagh, Future Neurol., 2009, 4, 167-177.

144 S. Schilling, U. Zeitschel, T. Hoffmann, U. Heiser, M. Francke, A. Kehlen, M. Holzer, B. Hutter-Paier, M. Prokesch, M. Windisch, W. Jagla, D. Schlenzig, C. Lindner, T. Rudolph, G. Reuter, H. Cynis, D. Montag, H.-U. Demuth and S. Rossner, Nat. Med., 2008, 14, 1106.

145 J. L. Frost, K. X. Le, H. Cynis, E. Ekpo, M. Kleinschmidt, R. M. Palmour, F. R. Ervin, S. Snigdha, C. W. Cotman, T. C. Saido, R. J. Vassar, P. S. George-Hyslop, T. Ikezu, S. Schilling, H.-U. Demuth and C. A. Lemere, Am. J. Pathol., 2013, 183, 369-381.

146 T. Hoffmann, A. Meyer, U. Heiser, S. Kurat, L. Böhme, M. Kleinschmidt, K.-U. Bühring, B. Hutter-Paier, M. Farcher, H.-U. Demuth, I. Lues and S. Schilling, J. Pharmacol. Exp. Ther., 2017, 362, 119-130.

147 Y. Hori, S. Takeda, H. Cho, S. Wegmann, T. M. Shoup, K. Takahashi, D. Irimia, D. R. Elmaleh, B. T. Hyman and E. Hudry, J. Biol. Chem., 2015, 290, 1966-1978.

148 J. Budni, M. L. Garcez, J. d. Medeiros, E. Cassaro, T. Bellettini-Santos, F. Mina and J. Quevedo, Curr. Alzheimer Res., 2016, 13, 1319-1329.

149 S. M. Roy, V. L. Grum-Tokars, J. P. Schavocky, F. Saeed, A. Staniszewski, A. F. Teich, O. Arancio, A. D. Bachstetter, S. J. Webster, L. J. Van Eldik, G. Minasov, W. F. Anderson, J. C. Pelletier and D. M. Watterson, ACS Chem. Neurosci., 2015, 6, 666-680.

150 J. J. Alam, J. Alzheimer's Dis., 2015, 48, 219-227.

151 T. Alkam, A. Nitta, H. Mizoguchi, K. Saito, M. Seshima, A. Itoh, K. Yamada and T. Nabeshima, Behav. Brain Res., 2008, 189, 100-106.

152 C. Holmes, C. Cunningham, E. Zotova, D. Culliford and V. H. Perry, Neurology, 2011, 77, 212-218.

153 J. Butchart, L. Brook, V. Hopkins, J. Teeling, U. Püntener, D. Culliford, R. Sharples, S. Sharif, B. McFarlane, 
R. Raybould, R. Thomas, P. Passmore, V. H. Perry and C. Holmes, Neurology, 2015, 84, 2161-2168.

154 A. Maelicke, A. Hoeffle-Maas, J. Ludwig, A. Maus, M. Samochocki, U. Jordis and A. K. E. Koepke, J. Mol. Neurosci., 2010, 40, 135-137.
155 R. S. Bitner, S. Markosyan, A. L. Nikkel and J. D. Brioni, Neuropharmacology, 2011, 60, 460-466.

156 X. Song, M. O. Jensen, V. Jogini, R. A. Stein, C.-H. Lee, H. S. McHaourab, D. E. Shaw and E. Gouaux, Nature, 2018, 556, 515-519. 